\title{
Generation of colonic IgA-secreting cells in the caecal patch
}

Kazunori Masahata1,2, Eiji Umemoto ${ }^{1,3}$, Hisako Kayama1,3, Manato Kotani ${ }^{4}$, Shota Nakamura ${ }^{5}$, Takashi Kurakawa', Junichi Kikuta4, Kazuyoshi Gotoh ${ }^{5}$, Daisuke Motooka ${ }^{5}$, Shintaro Sato ${ }^{6}$, Tomonori Higuchi ${ }^{7}$, Yoshihiro Baba ${ }^{8}$, Tomohiro Kurosaki ${ }^{8}$, Makoto Kinoshita1,3, Yosuke Shimada1, Taishi Kimura ${ }^{1}$, Ryu Okumura Akira Takeda ${ }^{1}$, Masaru Tajima9 ${ }^{9}$, Osamu Yoshie ${ }^{7}$, Masahiro Fukuzawa², Hiroshi Kiyono ${ }^{3,6}$, Sidonia Fagarasan ${ }^{10}$, Tetsuya lida ${ }^{5,11}$, Masaru Ishii ${ }^{3,4} \&$ Kiyoshi Takeda ${ }^{1,3}$

Gut-associated lymphoid tissues are responsible for the generation of IgA-secreting cells. However, the function of the caecal patch, a lymphoid tissue in the appendix, remains unknown. Here we analyse the role of the caecal patch using germ-free mice colonized with intestinal bacteria after appendectomy. Appendectomized mice show delayed accumulation of $\lg \mathrm{A}^{+}$cells in the large intestine, but not the small intestine, after colonization. Decreased colonic IgA ${ }^{+}$cells correlate with altered faecal microbiota composition. Experiments using photoconvertible Kaede-expressing mice or adoptive transfer show that the caecal patch $\lg \mathrm{A}^{+}$cells migrate to the large and small intestines, whereas Peyer's patch cells are preferentially recruited to the small intestine. $\operatorname{lgA}^{+}$cells in the caecal patch express higher levels of CCR10. Dendritic cells in the caecal patch, but not Peyer's patches, induce CCR10 on cocultured B cells. Thus, the caecal patch is a major site for generation of IgA-secreting cells that migrate to the large intestine.

\footnotetext{
${ }^{1}$ Laboratory of Immune Regulation, Department of Microbiology and Immunology, Graduate School of Medicine, WPI Immunology Frontier Research Center, Osaka University, Suita, Osaka 565-0871, Japan. ${ }^{2}$ Department of Pediatric Surgery, Graduate School of Medicine, Osaka University, Suita, Osaka 565-0871, Japan. ${ }^{3}$ Core Research for Evolutional Science and Technology, Japan Science and Technology Agency, Saitama 332-0012, Japan. ${ }^{4}$ Department of Immunology and Cell Biology, Graduate School of Medicine, WPI Immunology Frontier Research Center, Osaka University, Suita, Osaka 565-0871, Japan. ${ }^{5}$ Department of Infection Metagenomics, Genome Information Research Center, Research Institute for Microbial Diseases, Osaka University, Suita, Osaka 565-0871, Japan. ${ }^{6}$ Division of Mucosal Immunology, Department of Microbiology and Immunology, Institute of Medical Science, The University of Tokyo, Tokyo 108-8639, Japan. ${ }^{7}$ Department of Microbiology, Kinki University Faculty of Medicine, Osaka-Sayama, Osaka 589-8511, Japan. ${ }^{8}$ Laboratory of Lymphocyte Differentiation, WPI Immunology Frontier Research Center, Osaka University, Suita, Osaka 565-0871, Japan. ${ }^{9}$ The Institute of Experimental Animal Sciences, Faculty of Medicine, Osaka University, Suita, Osaka 565-0871, Japan. ${ }^{10}$ Laboratory for Mucosal Immunity, Center for Integrative Medical Sciences, RIKEN, Yokohama 230-0045, Japan. ${ }^{11}$ Laboratory of Genomic Research on Pathogenic Bacteria, International Research Center for Infectious Diseases, Research Institute for Microbial Diseases, Osaka University, Suita, Osaka 565-0871, Japan. Correspondence and requests for materials should be addressed to K.T. (email: ktakeda@ongene.med.osaka-u.ac.jp).
} 
ntestinal lamina propria plasma cells secrete IgA as a dimer, which is transported to the intestinal lumen by polymeric immunoglobulin receptor ${ }^{1-4}$. In the intestinal lumen, secretory IgA binds pathogens and pathogen-derived antigens to limit their invasion into the body ${ }^{5,6}$. In addition, secretory IgA contributes to the maintenance of gut homeostasis by regulating the activities and compositions of commensal bacteria ${ }^{5,7-9}$. Dysregulation of gut homeostasis caused by defective $\operatorname{IgA}$ responses can compromise host defenses against intestinal pathogenic bacteria and correlates with autoimmune diseases ${ }^{10-12}$.

IgA-secreting cells develop in gut-associated lymphoid tissues (GALTs) such as Peyer's patches and solitary intestinal lymphoid tissues (SILTs) including cryptopatches, colonic patches and isolated lymphoid follicles (ILFs). Peyer's patches and ILF contribute to generation of IgA-secreting cells by different mechanisms ${ }^{2,13,14}$. However, it still remains unclear where and how IgA acquires antigen specificities and diversities. So far, characterization of IgA has focused on plasma cells residing in the small intestine. It has recently been reported that IgAs derived from the small and large intestines have differential repertoires ${ }^{15}$. It has also been reported that CCR9 mediates migration of IgA-secreting cells to the small intestine but not the large intestine $\mathrm{e}^{16}$, whereas CCR10 is involved in migration to both the small and large intestines ${ }^{17}$. However, it remains unclear where IgA-secreting plasma cells that migrate to the large intestine are generated.

In the appendix, a blind-ended tract linking the caecum, are lymphoid clusters called caecal patches. Compared with human caecal patches, which are present as multiple small clusters, mice possess a single large lymphoid cluster in the appendix ${ }^{18}$. As with Peyer's patches, caecal patches are covered by a monolayer of epithelial cells, among which M cells are present. Antigen-specific immunoglobulin responses and immunoglobulin diversification have been reported to occur in the appendix of rabbits ${ }^{19,20}$. Contrary to the above-mentioned evidences indicating that caecal patches are related to Peyer's patches, electron microscopy analysis has indicated that $\mathrm{M}$ cells on caecal patches have differential morphology to those on Peyer's patches ${ }^{21}$. Furthermore, it has been reported that appendectomy ameliorates intestinal inflammation observed in $\mathrm{Tcra}^{-1-}$ mice or dextran sodium sulphate-treated mice ${ }^{18,22}$. Thus, caecal patches in the appendix are thought to possess unique functions compared with other GALTs. However, the roles of caecal patches in mucosal immune responses remain unclear.

In this study, we analysed the function of the mouse caecal patch using germ-free mice, in which intestinal IgA-secreting cells are severely decreased because of the absence of commensal bacteria. Surgical resection of the appendix results in slower accumulation of IgA-secreting cells in the large intestine, but not the small intestine, after conventionalization of germ-free mice. $\mathrm{IgA}^{+}$cells in the caecal patch migrate to both the large and small intestines, whereas those in Peyer's patches are preferentially recruited to the small intestine. $\mathrm{IgA}^{+}$cells generated in the caecal patch express increased levels of CCR10 compared with cells in Peyer's patches. Decreased number of colonic IgA-secreting cells correlates with altered composition of faecal microbiota in appendectomized mice at the early time point after colonization. These findings suggest that the caecal patch is a major site for the generation of IgA-secreting cells that migrate to the large intestine.

\section{Results}

Similar characteristics of caecal patches and Peyer's patches. There exists a single lymphoid cell cluster in the appendix of mice called caecal patch ${ }^{18}$ (Fig. 1a). We compared immunological aspects of the characteristics of the caecal patch and Peyer's patches by immunohistochemistry (Fig. 1b). The caecal patch showed similar patterns of expression of CD4, B220 and CD11c to Peyer's patches, which are composed of B-cell-rich follicles, T-cell-rich parafollicular areas and a CD11c ${ }^{+}$cell-rich subepithelial dome region. Flow cytometry analysis indicated that the caecal patch and Peyer's patches contained similar numbers of $\mathrm{IgM}^{+} \mathrm{B}$ cells, $\mathrm{IgA}^{+} \mathrm{B}$ cells, $\mathrm{CD} 4^{+}$cells and $\mathrm{CD}^{+} \mathrm{c}^{+}$cells (Fig. 1c, Supplementary Fig. 1). In addition, mRNA expression of genes encoding APRIL, BAFF and AID, which are involved in the class switching of immunoglobulin, in the caecal patch was equivalent to that observed in Peyer's patches and mesenteric lymph nodes (Fig. 1d). Peyer's patches in germ-free mice have been reported to be small ${ }^{23}$. Similarly, the size of the caecal patch in germ-free mice was reduced compared with specific-pathogen-free mice, indicating that the development of the caecal patch is dependent on commensal microbiota (Fig. 1e). Organogenesis of Peyer's patches has been reported to be initiated by the interaction of haematopoietic Ror $\mathrm{t}^{+}$lymphoid tissue inducer (LTi) cells and stromal cells, which receive lymphotoxin signalling from LTi cells via lymphotoxin $\beta$ receptor (LT $\beta R)$. Mice lacking $\operatorname{Ror} \gamma t\left(\operatorname{Rorc}(g t)^{\mathrm{gfp} / \mathrm{gfp}}\right.$ mice) showed impaired development of LTi cells, and accordingly lacked Peyer's patches ${ }^{24}$. aly/aly mice that had a mutated gene encoding NF- $\kappa \mathrm{B}$-inducing kinase (NIK), which mediates LT $\beta \mathrm{R}$ signalling, showed impaired development of Peyer's patches ${ }^{25}$. These mutant mice also showed impaired caecal patch development (Fig. 1f). As previously reported, Peyer's patch cells from T-cell-deficient $\left(\mathrm{Tcrb}^{-/-} \mathrm{Tcrd}^{-/-}\right)$mice produced lower, but substantial, amounts of IgA than those of the wild-type mice ${ }^{26-28}$ (Fig. 1g). IgA production from caecal patch cells of Tcrb ${ }^{-1-}$ Tcrd $^{-}$- mice was also similarly reduced, thus indicating that

Figure 1 | Similar immunological characteristics of the caecal patch and Peyer's patches. (a) Haematoxylin and eosin staining of the caecal patch (CP) in the appendix and Peyer's patches (PP) in the small intestine of specific-pathogen-free mice. Scale bars, $100 \mu \mathrm{m}$. (b) Distribution of immune cells in CP and PP. Frozen sections were stained for B220 (green), CD4 (red), CD11c (grey) and DAPI (blue), and analysed by confocal fluorescence microscopy. Scale bars, $100 \mu \mathrm{m}$. (c) B-cell populations in CP and PP of specific-pathogen-free (SPF) mice. Cells were stained with anti-lgA, IgM and B220 mAbs, and analysed by flow cytometry. Numbers within dot plots indicate percentages of cells in respective areas. (d) Expression of immunoglobulin class switchingrelated genes. Expression of mRNA for Tnfsf13 (encoding APRIL), Tnfsf13c (encoding BAFF) and Aicda (encoding AID) in PP, CP and mesenteric lymph node (MLN) were quantitatively analysed by real-time RT-PCR, and normalized to that of Gapdh. Data represent mean \pm s.d. ( $n=4$ per group), and representations of two independent experiments are shown. (e) Development of the caecal patch in SPF or germ-free (GF) mice. Left: gross appearance of the appendix. The caecal patch was visualized based on a B220 ${ }^{+}$cluster of whole-mount staining. Middle and right: haematoxylin and eosin staining of the appendix. The boxed areas in the middle panels are enlarged on the right. Scale bars, $1 \mathrm{~mm}$ (left), $300 \mu \mathrm{m}$ (middle) and $100 \mu \mathrm{m}$ (right). (f) Development of the caecal patch in Rorc $(g t)^{g f p /+}$ or Rorc $(g t)^{g f p / g f p}$ mice (upper) and WT or aly/aly mice (lower). Arrows indicate CP $(\mathbf{e}, \mathbf{f})$. Original magnification, $\times 7$ (left panels in $\mathbf{e}$ and $\mathbf{f}$ ). Scale bars, $1 \mathrm{~mm}$. (g) IgA production by mononuclear cells from PP and CP. Mononuclear cells from PP and CP of WT and $\mathrm{Tcrb}^{-/}-\mathrm{Tcrd}^{-/}$mice were cultured for 3 days and the supernatant was analysed by ELISA. Data represent mean \pm s.d. of triplicate samples in one experiment, and representations of two independent experiments are shown. Statistical analyses were performed with the Student's $t$-test. ${ }^{\star} P<0.05$. 
the caecal patch as well as Peyer's patches mediate both T celldependent and -independent IgA inductions. Thus, the caecal patch and Peyer's patches show analogous features of immunological structures, function and developmental processes.

Delayed colonic $\operatorname{IgA}^{+}$cell recruitment without caecal patch. Given that the caecal patch showed similar properties to Peyer's patches, which are typical GALTs mediating immune responses, we investigated the immunological function of the caecal patch by generating caecal patch-deficient mice. To assess the effect of caecal patch deficiency on the development of intestinal immunity, we utilized germ-free mice, which showed normal development of the adaptive immune system after bacterial colonization in the gut. We removed the appendix of germ-free mice by surgery, and then transferred and reared them in a conventionalized (specific-pathogen-free) environment (Supplementary Fig. 2). At 4 weeks after conventionalization, a

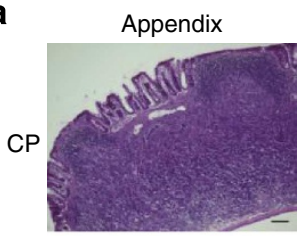

Small intestine

PP

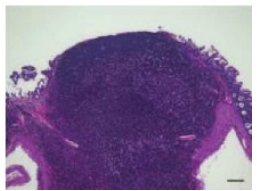

b

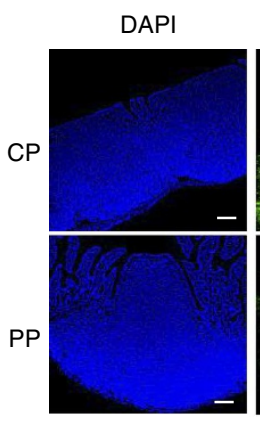

B220

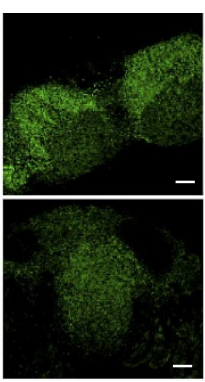

CD4

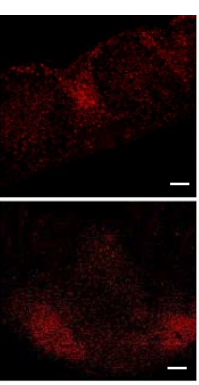

CD11c
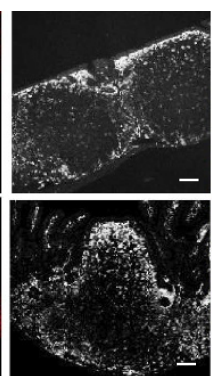

Merge

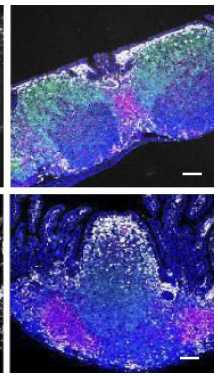

C

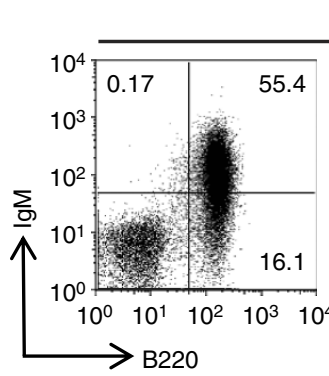

PP

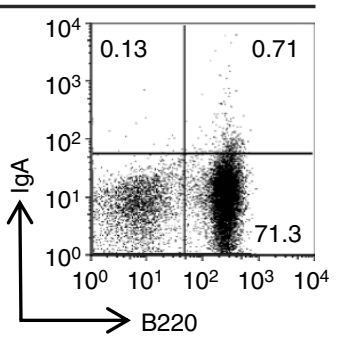

d

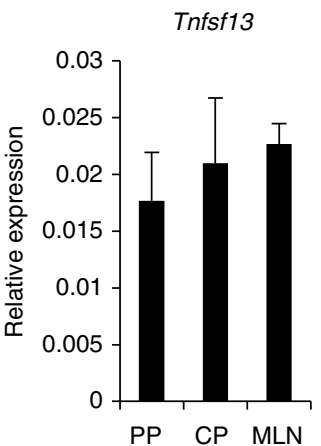

Tnfsf13c

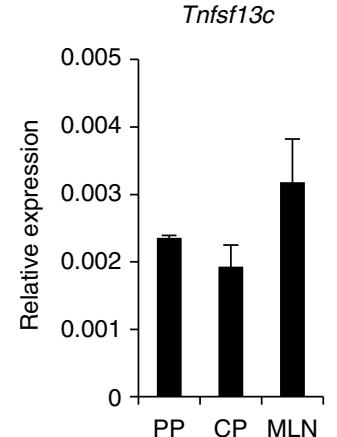

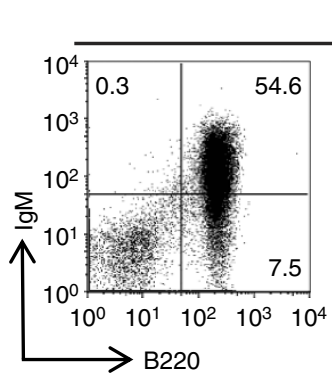

$\mathrm{CP}$

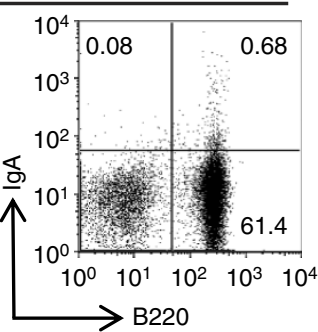

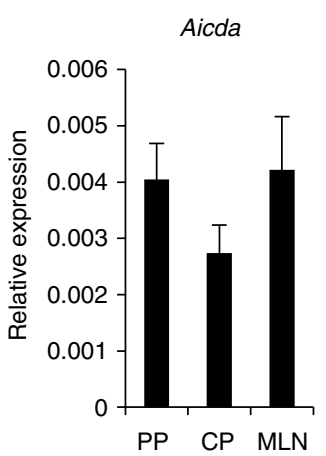
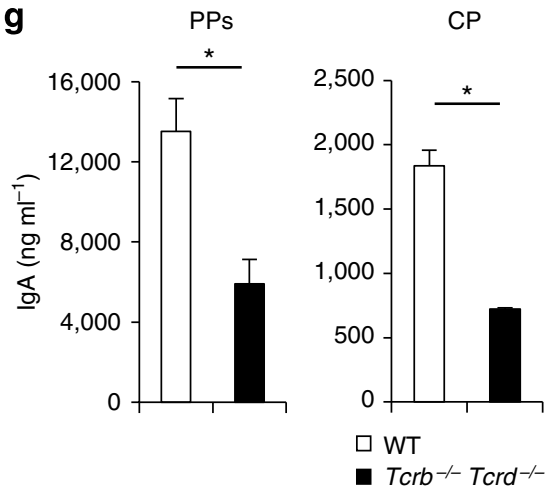

e

Appendix

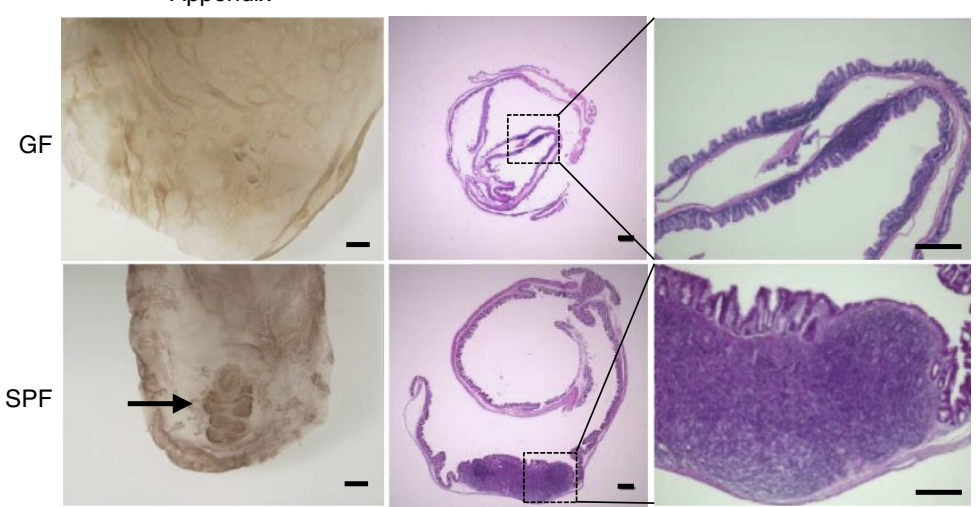

f

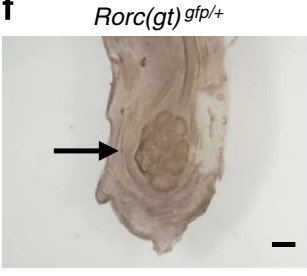

WT

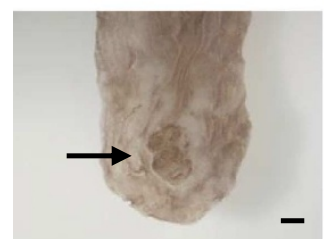

$\operatorname{Rorc}(g t) g f p / g f p$

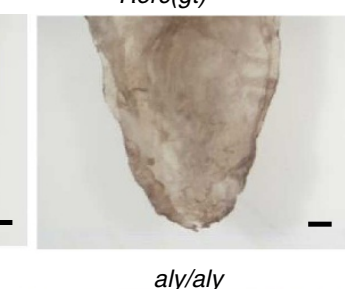


mice were analysed for the number of IFN- $\gamma$-, IL-17- and IL-10producing $\mathrm{CD}^{+}{ }^{+} \mathrm{T}$ cells and $\mathrm{IgA}^{+}$cells in the small and large intestines (Fig. 2a,b and Supplementary Fig. 3). IFN- $\gamma$-, IL-17and IL-10-producing $\mathrm{CD} 4{ }^{+} \mathrm{T}$ cells all increased in numbers similarly in the small and large intestines of sham-operated and appendectomized mice. $\operatorname{IgA}{ }^{+}$cells in the small intestine of shamoperated and appendectomized mice also increased to a similar extent after conventionalization. However, the number of $\operatorname{Ig} \mathrm{A}^{+}$ cells in the large intestine markedly decreased in appendectomized mice compared with sham-operated mice. The decrease in number of $\operatorname{IgA}^{+}$cells in large intestinal lamina propria was further confirmed by immunohistochemical analysis (Fig. 2c). $\mathrm{IgA}^{+}$cells were scarcely observed in germ-free mice, and conventionalization of sham-operated germ-free mice increased the number of $\operatorname{IgA}{ }^{+}$cells. In contrast, the number of $\operatorname{IgA}{ }^{+}$cells in large intestinal lamina propria did not dramatically increase after conventionalization of germ-free mice with the appendectomy at 4 weeks after conventionalization. We next analysed concentration of secretory IgA in faeces and serum at 4 weeks after conventionalization (Fig. 2d). Levels of secretory IgA in faeces, but not in serum, in appendectomized mice were lower than those in sham-operated mice. Thus, accumulation of IgA-secreting cells selectively decreased in the large intestine of appendectomized mice at 4 weeks after conventionalization. We then analysed time-dependent increase of $\operatorname{IgA}^{+}$cells in the large intestine by measuring $\operatorname{IgA}^{+}$cell number at 2,4 and 8 weeks after conventionalization (Fig. $3 \mathrm{a}-\mathrm{c}$ ). At 2 weeks as well as 4 weeks, the number of $\mathrm{IgA}^{+}$cells was markedly decreased in appendectomized mice. However, at 8 weeks, the number of IgA ${ }^{+}$cells of appendectomized mice was comparable to that of sham-operated mice. Taken together, these findings indicate that accumulation of IgA-secreting cells to the large intestine was delayed in mice with appendectomy.

\footnotetext{
Altered faecal microbiota composition in appendectomized mice. As secretory IgA is responsible for the control of intestinal bacteria, we analysed the composition of faecal microbiota in appendectomized and sham-operated mice at 4 weeks after conventionalization by pyrosequence-based $16 \mathrm{~S}$ rRNA gene profiling. The rarefaction curve showed that the estimated operational taxonomic units (OTUs) of appendectomized mice were less abundant than those of sham-operated mice and that the sufficient sequencing depth has been achieved in both groups (Fig. 4a). In the class distribution, the relative abundance of several bacterial groups such as Bacilli, Erysipelotrichi and Gammaproteobacteria in appendectomized mice was higher than that in sham-operated mice; Mollicutes, Deferribacteres, Betaproteobacteria and Deltaproteobacteria were less abundant in appendectomized mice (Fig. 4b, Supplementary Table 1). Analyses at the other levels also showed that the relative abundance of many bacterial groups was significantly different between appendectomized and sham-operated groups (Supplementary Fig. 4a-c, Supplementary Tables 2-4). Principal coordinate analysis using the relative abundance of OTUs indicated that bacterial community of appendectomized mice was clearly separated from that of sham-operated mice at 4 weeks after conventionalization (Fig. 4c, Supplementary Data 1). We then analysed faecal microbiota composition in appendectomized mice at 8 weeks after conventionalization when colonic IgA-secreting cells were normalized. Bacterial community of appendectomized mice at 8 weeks after conventionalization was similar to that of sham-operated mice (Fig. $4 \mathrm{~d}, \mathrm{e}$ ). Thus, at 4 weeks after conventionalization, microbiota composition was altered in mice with appendectomy, but in accordance with normalized numbers of colonic IgA-secreting cells at 8 weeks, the alteration of faecal microbiota composition disappeared.
}

To exclude the possibility that the incision of the appendix itself caused the slow accumulation of IgA-secreting cells and the altered composition of microbiota in the large intestine, we cut and sutured the appendix without excision, and analysed the number of IgA-secreting cells and faecal microbiota at 4 weeks after conventionalization (Supplementary Fig. 5a-d). In these enterotomized mice, no alteration of the IgA-secreting cells and microbiota composition was observed compared with sham-operated mice, which underwent incision of the abdomen alone. Thus, appendectomized mice, which showed delayed accumulation of $\operatorname{IgA}{ }^{+}$cells in the large intestine, had altered configurations of faecal microbiota at 4 weeks after conventionalization.

Recruitment of caecal patch IgA ${ }^{+}$cells to the colon. We analysed the mechanisms for the slower increase of colonic IgAsecreting cells in appendectomized mice using Kaede-transgenic mice, in which in vivo cell migration can be monitored ${ }^{29}$. Kaede is a photoconvertible protein, changing fluorescence from green to red with exposure of violet light. We generated Kaede bone marrow chimeric mice, in which bone marrow cells were reconstituted with those of Kaede-transgenic mice. The caecal patch from Kaede bone marrow chimeric mice was exposed to violet light for $5 \mathrm{~min}$ to induce photoconversion of Kaede proteins expressed in haematopoietic cell types present in this region. After exposure, $93.8 \pm 3.2 \%$ of cells isolated from caecal patches expressed a red fluorescence signal (Kaede-red) (Supplementary Fig. 6). At 3 and 7 days after photoconversion, the number of Kaede-red cells gradually decreased in the caecal patch (Fig. 5a). Accordingly, Kaede-red $\operatorname{IgA}^{+} \mathrm{B}_{220^{-}}$cells increased similarly in the lamina propria of the small and large intestines at the 7-day time point (Fig. 5b). We also exposed Peyer's patches to violet light, and analysed migration of Peyer's patch-derived $\operatorname{IgA}^{+}$cells to intestinal lamina propria. Kaede-red $\mathrm{IgA}^{+}{\mathrm{B} 220^{-}}^{-}$cells were observed both in the small and large intestines at 7 days after photoconversion. However, the percentage of Kaede-red $\operatorname{IgA}^{+}$cells in total $\operatorname{IgA}^{+}$cells was markedly reduced in the large intestine compared with the small intestine (Fig. 5c). These findings indicate that IgA-secreting cells generated in the caecal patch migrate to both the small and large intestines, but IgA-secreting cells generated in Peyer's patches preferentially migrate to the small intestine. To corroborate these findings, we transferred $\mathrm{CD} 45.2^{+} \mathrm{B} 220^{+}$cells from caecal patches and Peyer's patches into CD45.1 ${ }^{+}$mice. At 7 days after transfer, CD $45.2^{+} \mathrm{IgA}{ }^{+}$cells in the small and large intestines of CD $45.1^{+}$mice were measured (Fig. 5d). Similarly to the results obtained from experiments using Kaede bone marrow chimeric mice, $\operatorname{IgA}^{+}$cells isolated from caecal patches migrated to both the small and large intestines. In contrast, $\operatorname{IgA}^{+}$cells isolated from Peyer's patches were preferentially recruited to the small intestine. Taken together, these findings suggest that IgAsecreting cells generated in Peyer's patches mainly migrate to the small intestine, whereas IgA-secreting cells generated in the caecal patch are programmed to be recruited to both the small and large intestines. In accordance with these findings, the caecum/appendix showed a similar pattern of bacterial composition to the large intestine rather than the small intestine (Supplementary Figs 7 and 8), indicating that large intestine-types of intestinal bacteria residing in the caecum/ appendix may contribute to the generation of $\operatorname{IgA}$ that acts on bacteria of the large intestine.

Enhanced CCR10 expression in caecal patch $\operatorname{IgA}{ }^{+}$cells. It has been reported that CCR9 and CCR10 mediate the migration of $\mathrm{IgA}^{+}$cells to the intestinal lamina propria ${ }^{30}$. Therefore, we used 
Large intestine

IL-10

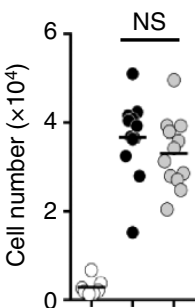

a

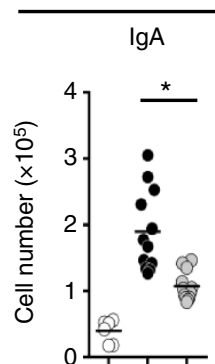

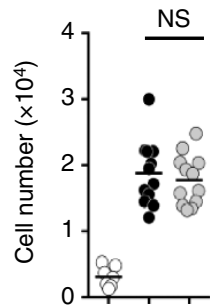

Small intestine

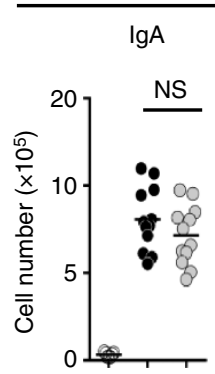

IL-17

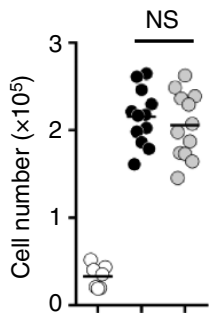

IL-10

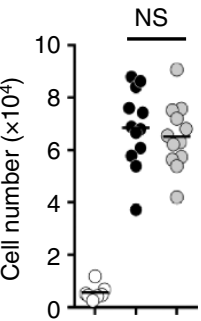

IFN- $\gamma$

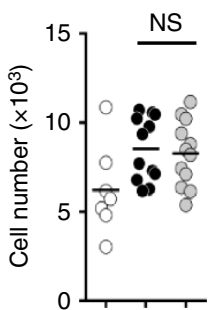

IFN- $\gamma$

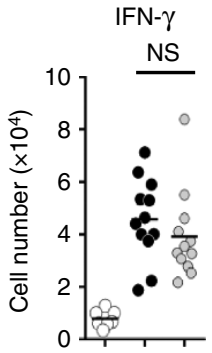

$\bigcirc$ GF Sham $\bigcirc$ Appendectomy

C

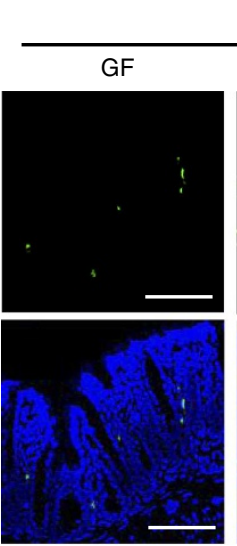

Large intestine

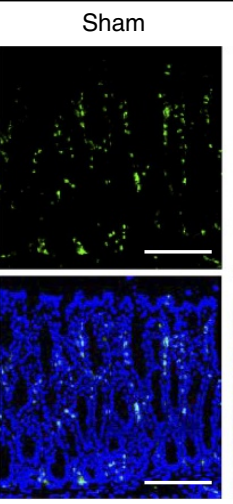

Appendectomy
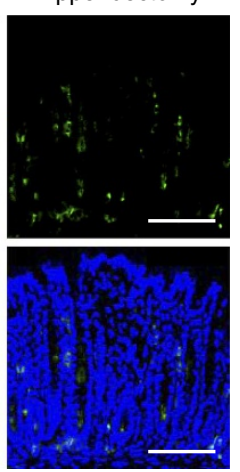

전 $10^{1}$

b

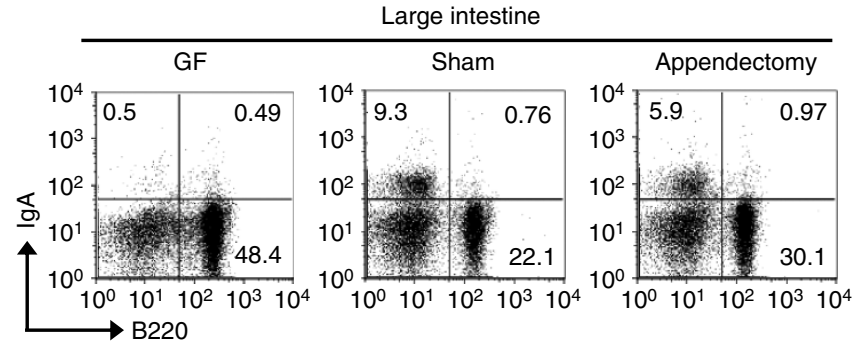

Small intestine

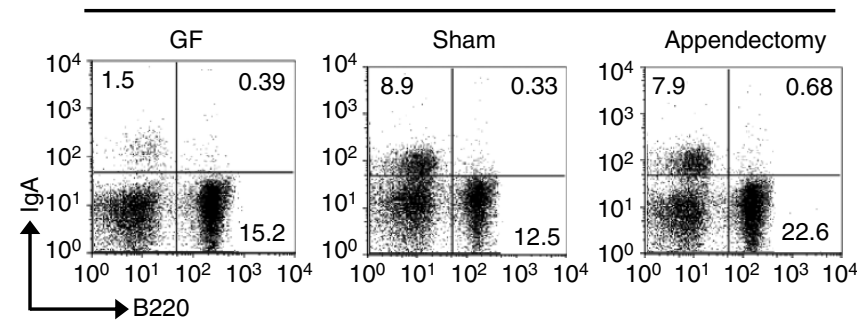

d

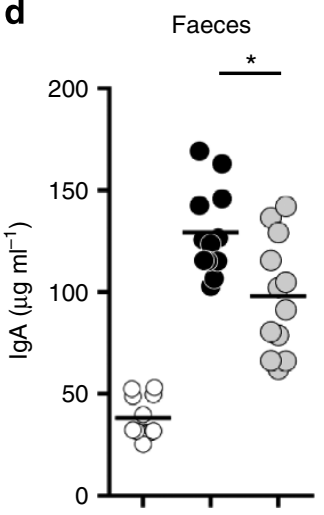

Small intestine

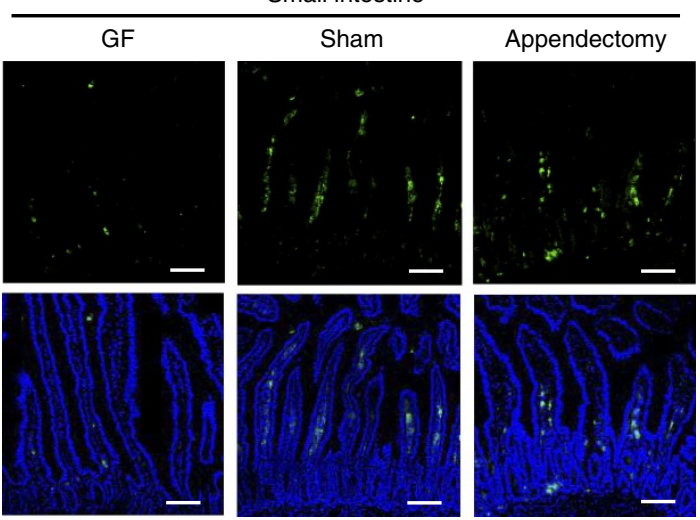

Sera

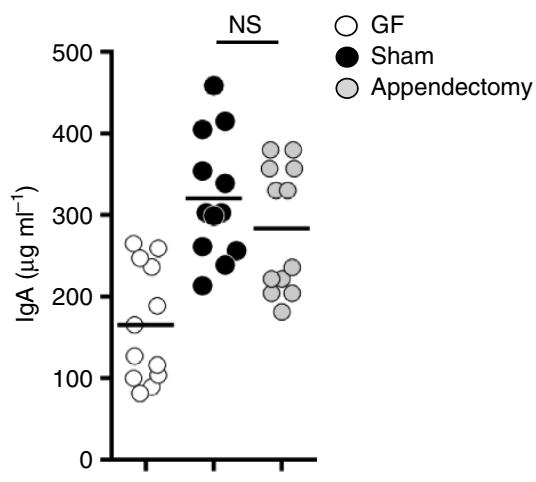

Figure 2 | Decreased IgA-secreting cells in large intestinal lamina propria of appendectomized germ-free mice after conventionalization. (a,b) Lamina propria lymphocytes were isolated from appendectomized or sham-operated germ-free(GF) mice at 4 weeks after conventionalization, and stained for surface IgA/B220 or intracellular IL-17/IFN- $\gamma /$ IL-10 in CD4 ${ }^{+}$population. (a) Total numbers of IgA ${ }^{+} \mathrm{B}_{2} 20^{-}$cells as well as IL-17-, IFN- $\gamma-$ and $\mathrm{IL}-10$-positive $\mathrm{CD}^{+}{ }^{+}$cells in the large (upper) and the small intestine (lower) are shown. Each symbol represents an individual mouse, and horizontal bars indicate the mean. (b) Representative dot plots for cells stained with anti-lgA and B220 of appendectomized and sham-operated mice. Numbers within plots indicate percentages of cells in respective areas. (c) Distribution of $\lg A^{+}$cells in the small and large intestines. Frozen sections were stained with anti-lgA mAb (green) and DAPI (blue). Scale bars, $100 \mu \mathrm{m}$. (d) Faeces and sera were collected from appendectomized ( $n=12$ ) or sham-operated mice $(n=12)$ at 4 weeks after conventionalization and GF mice $(n=12)$, and IgA levels of faeces and sera were determined by ELISA. Each symbol represents an individual mouse, and horizontal bars indicate the mean. Statistical analyses were performed with the Student's $t$-test. ${ }^{*} P<0.05$. NS, not significant. 
a
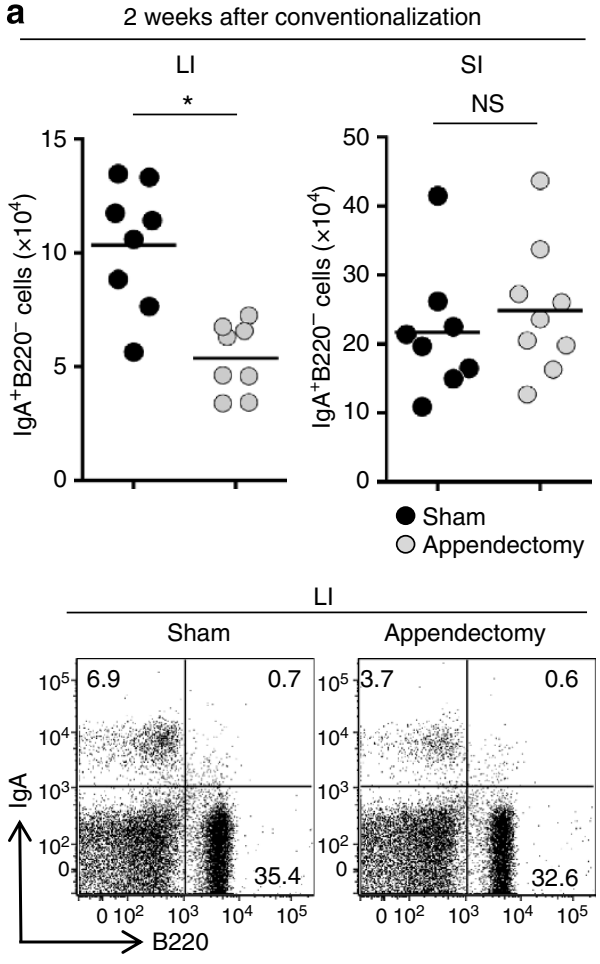

SI
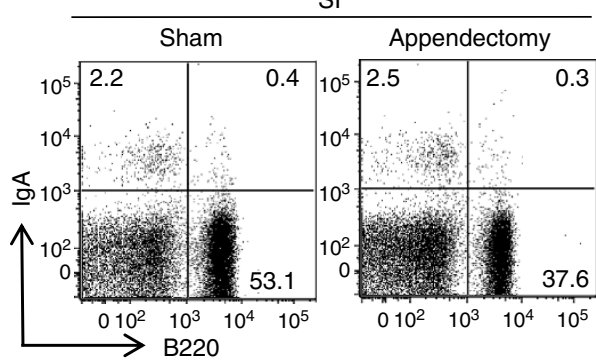

C

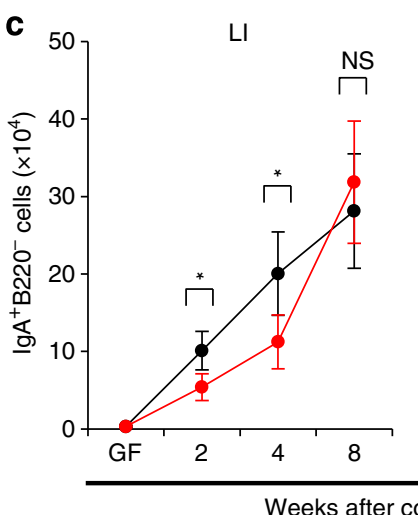

b
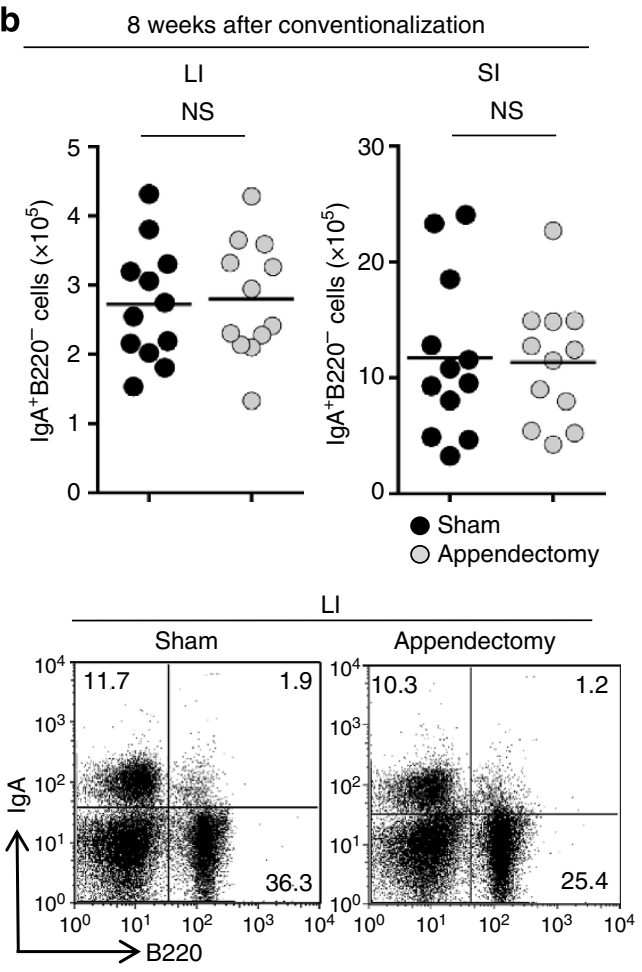

SI

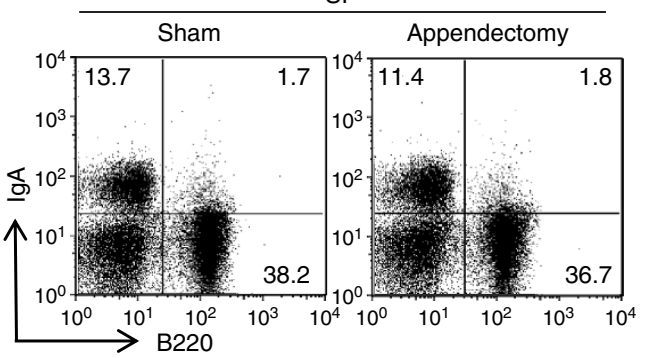

Weeks after conventionalization

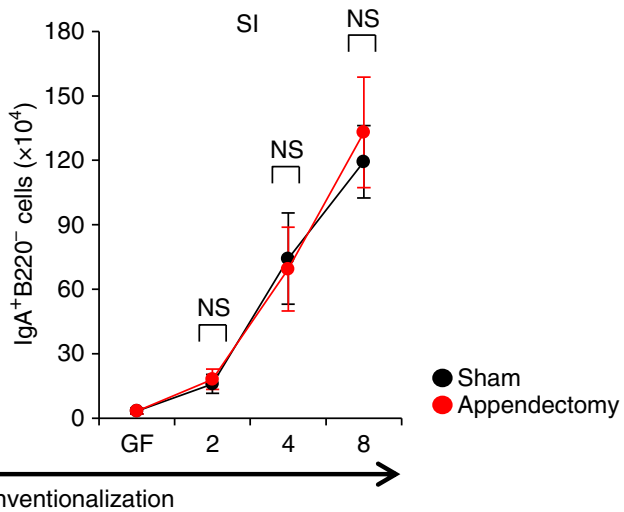

Figure 3 | The number of lgA-secreting cells in the large intestine at $\mathbf{2}$ and $\mathbf{8}$ weeks after conventionalization. (a,b) Lamina propria lymphocytes were prepared from appendectomized or sham-operated mice at 2 weeks (a) and 8 weeks (b) after conventionalization, and analysed for the expression of surface IgA and B220 by flow cytometry. Total numbers of IgA ${ }^{+}$B220- ${ }^{-}$cells in the small or large intestines are shown. Each symbol represents an individual mouse, and horizontal bars indicate the mean. Representative dot plots of intestinal leukocytes prepared from appendectomized and sham-operated mice are shown. Numbers within plots indicate percentages of cells in respective areas. (c) The numbers of IgA ${ }^{+} \mathrm{B}^{2} 2 \mathrm{O}^{-}$cells in the small and large intestines of appendectomized and sham-operated mice at indicated time points after conventionalization. The experiments were performed more than two times with similar results. Data represent mean \pm s.d. (four mice per group). SI, small intestine; LI, large intestine. Statistical analyses were performed with the Student's $t$-test. ${ }^{\star} P<0.05$. NS: not significant.

anti-CCR9 $\mathrm{mAb}$ and CCL27-Fc chimera protein to analyse surface expression of CCR9 and CCR10 on IgA ${ }^{+}$cells, which were positive for the plasmablast marker CD138 (Supplementary
Fig. 9), in the caecal patch and Peyer's patch (Fig. 6a,b). CCR9 was similarly expressed on IgA ${ }^{+}$cells in the caecal patch and Peyer's patch. In contrast, expression of CCR10 determined by 
a

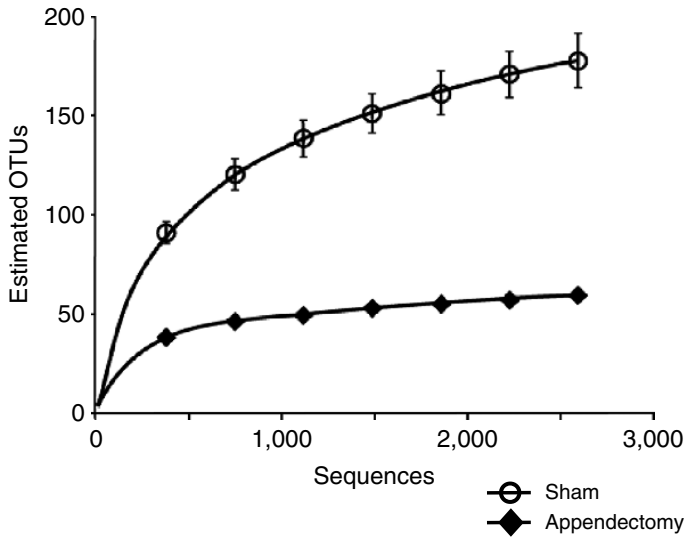

C

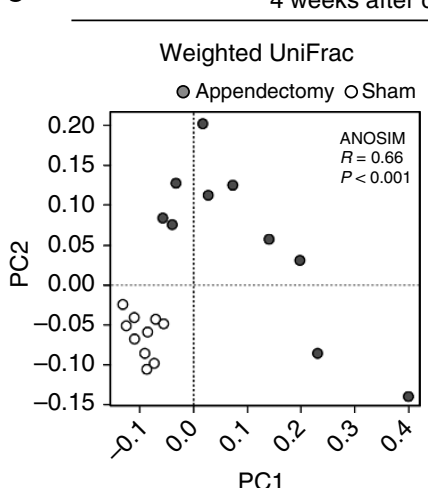

4 weeks after conventionalization

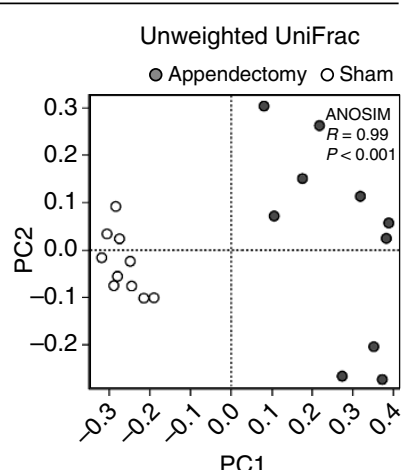

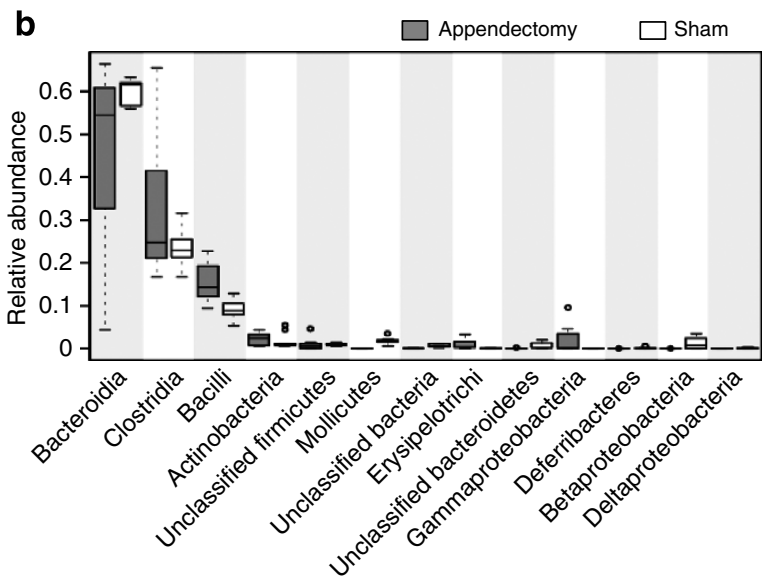

d

8 weeks after conventionalization

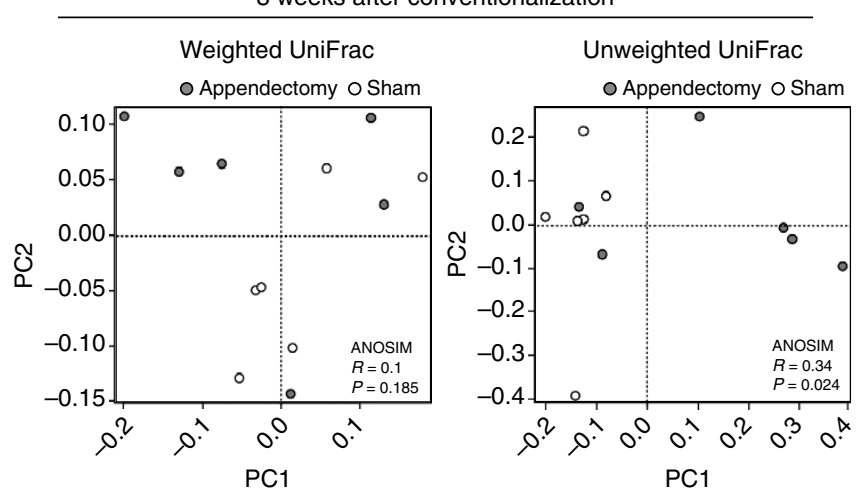

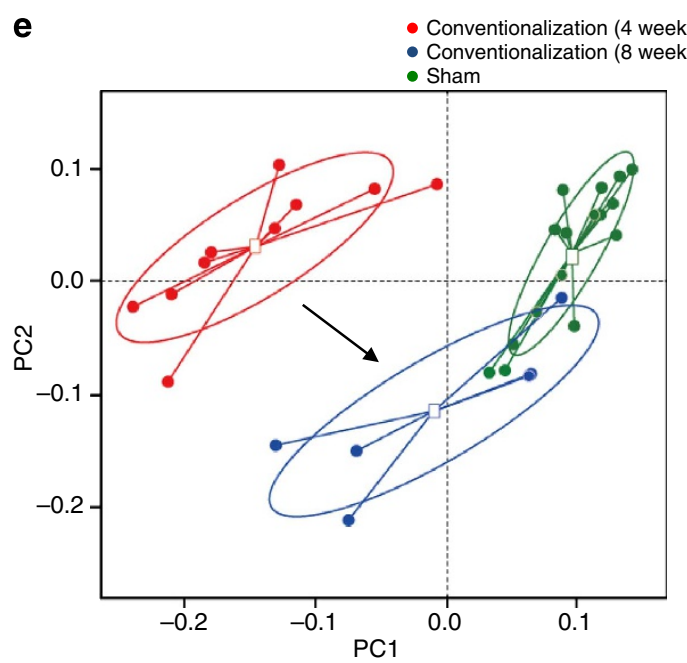

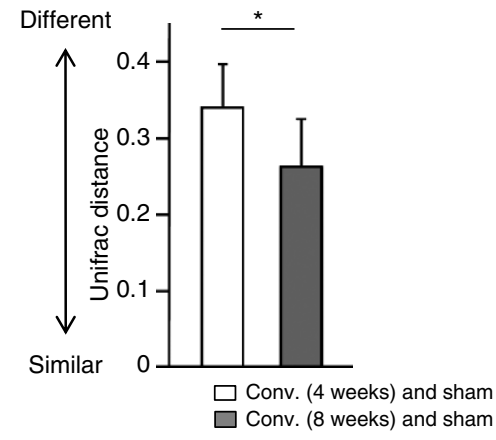

Figure 4 | Altered composition of faecal microbiota in appendectomized mice. Faecal microbiota in mice with appendectomy ( $n=10)$ and sham-surgery $(n=10)$ at 4 weeks and 8 weeks after conventionalization was analysed by pyrosequence-based 16S rRNA gene profiling. (a) Rarefaction curves of sham-operated and appendectomized groups at 4 weeks after conventionalization. The vertical axis shows the number of observed species that would be expected to be found after sampling the number of sequences shown on the horizontal axis. The number of taxa was at a $3 \%$ dissimilarity level. Data represent mean \pm s.d. (b) A box plot of class level-bacterial composition of appendectomized and sham-operated mice at 4 weeks after conventionalization. The box for each group represents the interquartile range (25-75th percentile) and the line within the box is the median value. The bottom and top bars indicate the 10th and 90th percentile, respectively. Open circles represent outlier values. The results of statistical test were described in Supplementary Table 1. (c,d) The principal coordinate analysis (PCoA) using OTUs based on the weighted (left) and unweighted (right) UniFrac distances. Faecal microbiota of appendectomized mice at 4 weeks (c) or 8 weeks (d) after conventionalization was compared with that of sham-operated mice. For statistical analysis, ANOSIM was calculated using R package 'Vegan'. (e) PCoA of faecal microbiota in mice with appendectomy and sham-surgery at 4 weeks and 8 weeks after conventionalization using OTUs (left). Red, blue and green circles indicate the clusters of mice with appendectomy at 4 weeks, 8 weeks after conventionalization and sham-operated mice, respectively. The UniFrac distance is calculated between pairs of samples (right). Statistical analyses were performed with the Student's $t$-test. ${ }^{\star} P<0.05$. 
CCL27-binding in caecal patch IgA ${ }^{+}$cells was markedly higher than $\operatorname{IgA}{ }^{+}$cells in Peyer's patches.

Dendritic cells (DCs) residing in Peyer's patches instruct B cells to secrete microbe-specific IgA ${ }^{31}$, and induce CCR9 expression on IgA-secreting cells ${ }^{32}$. Therefore, we analysed whether DCs in the caecal patch induce CCR10 expression on B cells (Fig. $6 c, d$ ). $\mathrm{CD}_{11 \mathrm{c}}{ }^{+} \mathrm{DCs}$ were isolated from Peyer's patches and caecal patches of mice treated with FMS-like tyrosine kinase 3 ligand (Flt3L) and cultured with splenic naive B cells. Peyer's patchderived and caecal patch-derived DCs induced expression of CCR9 on B cells. In contrast, Peyer's patch-derived DCs failed to induce CCR10 expression on cocultured B cells. However, B cells cocultured with caecal patch-derived DCs expressed increased

a

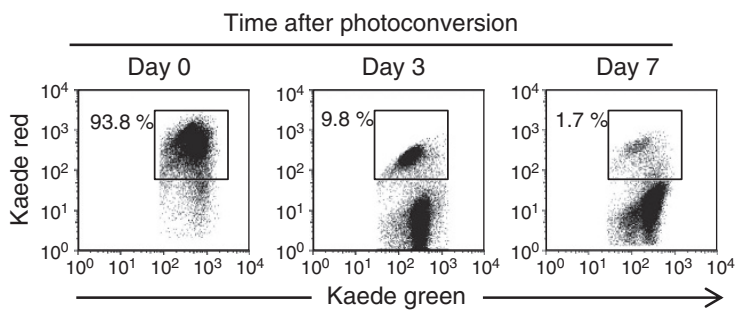

b
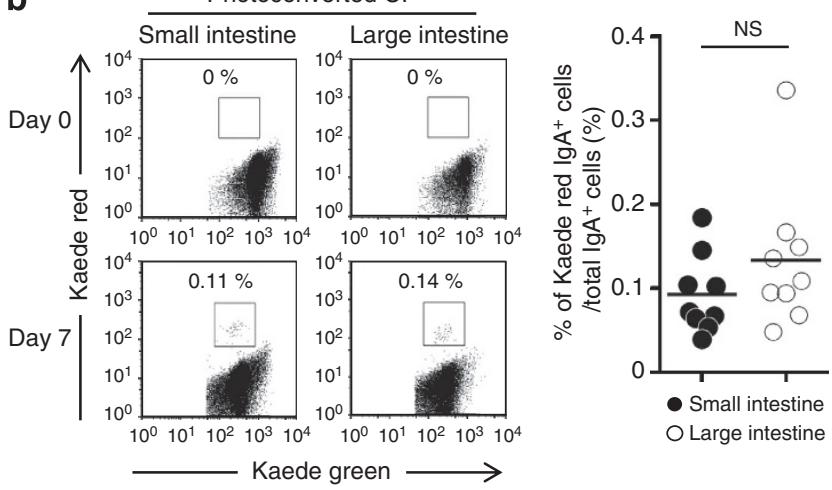

C

C Photoconverted PP
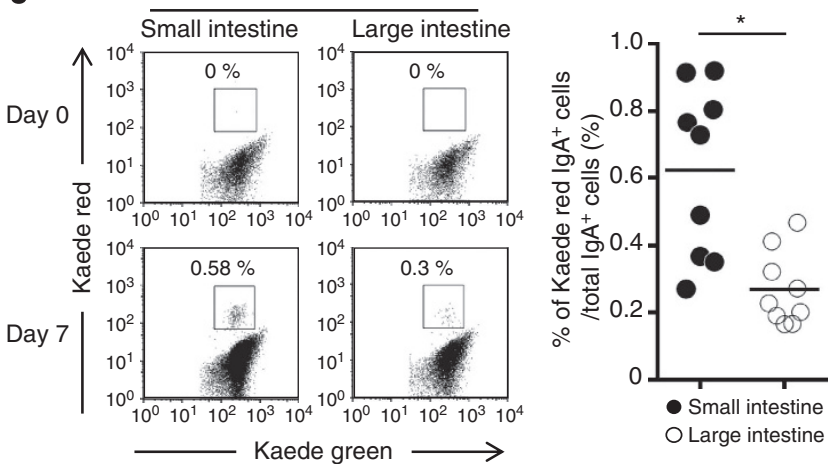

d
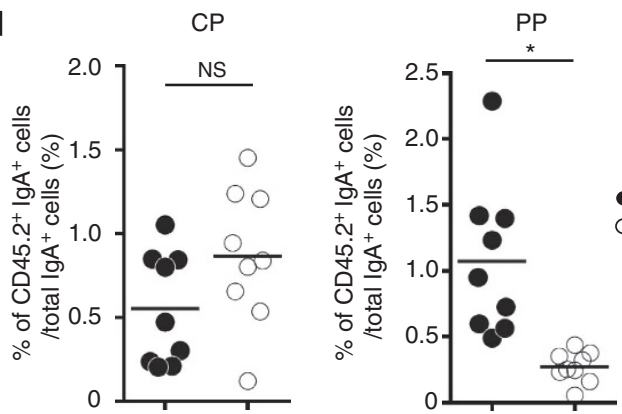

levels of CCR10. Thus, DCs residing in the caecal patch were able to induce CCR10 expression.

Increased colonic lymphoid clusters without caecal patch. ILFs are sites of generation of IgA-secreting cells with differential mechanisms to those from Peyer's patches ${ }^{26}$. In the absence of CCR10, SILTs including ILFs have been reported to enlarge and increase in number, which contributed to the maintenance of a normal number of IgA-secreting cells in the intestine of Ccr10 ${ }^{-1-}$ mice ${ }^{17}$. Therefore, we measured the number of SILTs in the large intestine of appendectomized mice by whole-mount staining of $\mathrm{B}_{22}{ }^{+}$cells at 8 weeks after conventionalization (Fig. 7). The number of SILTs in the small intestine did not alter in appendectomized mice. In contrast, there were more SILTs in the large intestine of appendectomized mice than that of shamoperated mice. In addition, the size of each SILT was slightly larger in the large intestine of appendectomized mice. Thus, normalization of colonic IgA-secreting cells at 8 weeks correlates with the increased and enlarged SILTs.

\section{Discussion}

In this study, we show that in the absence of the caecal patch, the number of IgA-secreting cells in the large intestine increased with markedly delayed kinetics after bacterial colonization. Subsequent analyses demonstrated that IgA-secreting plasmablasts migrate to the large and small intestines from the caecal patch, but plasmablasts in Peyer's patches are mainly recruited to the small intestines. DCs in caecal patches, but not in Peyer's patches, effectively induced expression of CCR10, which mediates recruitment of plasmablasts to both the small and large intestines. In line with the decreased number of IgA-secreting cells in the large intestine of appendectomized mice, the composition of microbiota in faeces altered compared with that of sham-operated mice at 4 weeks after conventionalization.

We generated mice lacking the caecal patch using germ-free mice that developed normal adaptive immunity after colonization of microbiota. Appendectomy has been performed in mice reared in specific-pathogen-free condition ${ }^{18,22}$. However, in this condition, mice suffered from peritonitis due to extravasation of microbiota via surgical wound sites, and are therefore unsuitable for analysis of intestinal immune responses in the

Figure 5 | Recruitment of caecal patch, but not Peyer's patch, IgA-secreting cells to the colon. (a) The caecal patch in the appendix from Kaede bone marrow chimeric mice were exposed to violet light for $5 \mathrm{~min}$ and resected immediately (day 0 ), or 3 and 7 days after violet light exposure. Cells from photoconverted caecal patches were subjected to flow cytometry at indicated time points to evaluate photoconversion. Numbers within plots indicate percentages of cells in respective areas. Data are representative of three independent experiments. $(\mathbf{b}, \mathbf{c})$ The caecal patch (CP) (b) or Peyer's patches (PP) (c) were exposed to violet light for $5 \mathrm{~min}$, and the percentages of Kaede-red $\lg \mathrm{A}^{+}$cells in total $\lg \mathrm{A}^{+}$cells in the intestines were analysed at 7 days after photoconversion. Representative dot plots of cells in the intestinal lamina propria are shown (left). Right panel shows the percentages of photoconverted $\lg \mathrm{A}^{+}$cells in total IgA ${ }^{+}$cells of intestinal lamina propria. Each symbol represents an individual mouse, and horizontal bars indicate the mean. (d) $\mathrm{B} 22 \mathrm{O}^{+}$cells from CD45.2 mice were transferred into CD45.1 C57BL/6 recipient mice. $\mathrm{CD} 45.2^{+} \mathrm{IgA}{ }^{+}$cells in intestinal lamina propria from CD 45.1 C57BL/6 mice were analysed at 7 days after cell transfer. Data show the percentages of CD $45.2^{+} \operatorname{lgA}{ }^{+}$cells in total $\operatorname{lgA}{ }^{+}$cells of intestinal lamina propria. Each symbol represents an individual mouse, and horizontal bars indicate the mean. Statistical analyses were performed with the Student's $t$-test. ${ }^{\star} P<0.05$. NS, not significant. 
a

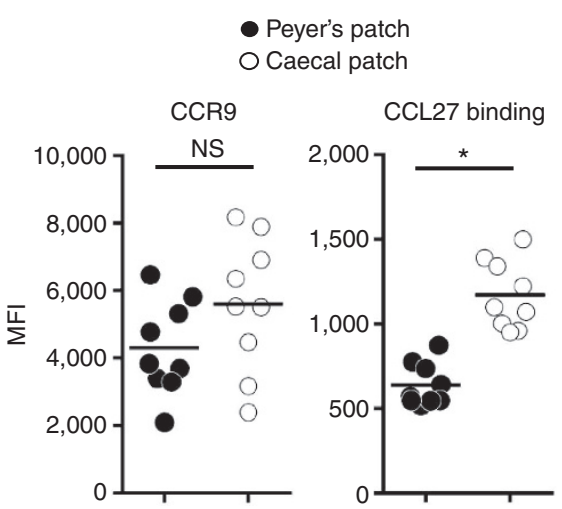

b
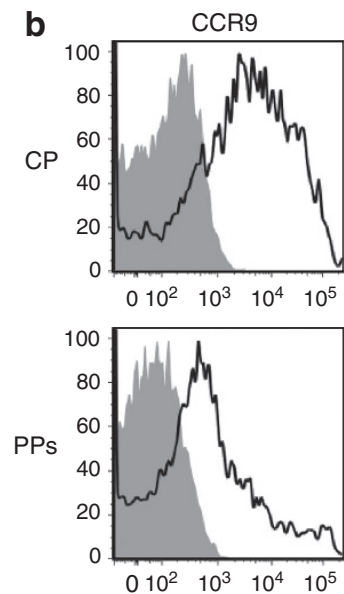

CCL27 binding
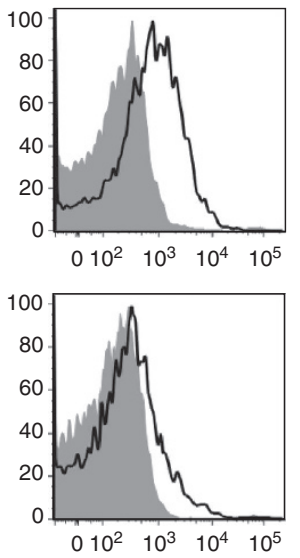

d

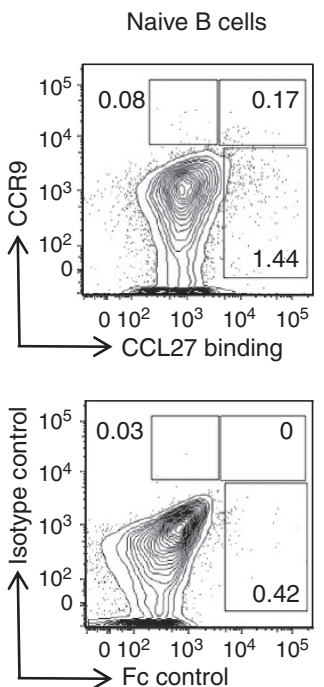

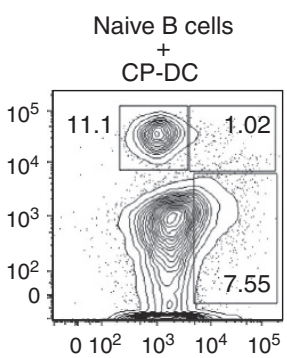
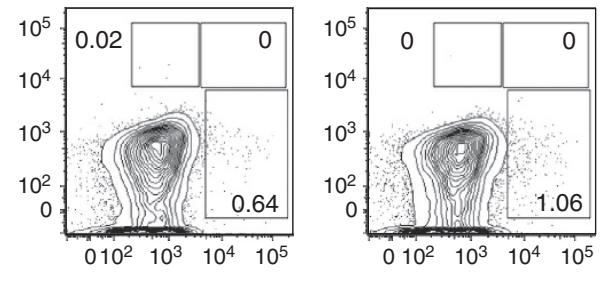

Figure 6 | Enhanced CCR10 expression in caecal patch IgA-producing cells. (a,b) Expression of CCR9 and CCR10 on IgA ${ }^{+}$cells in Peyer's patch and the caecal patch. IgA ${ }^{+} \mathrm{B} 220^{+}$cells prepared from Peyer's patches (PP) or caecal patch (CP) of specific-pathogen-free mice were analysed for expression of CCR9 and CCR10 using anti-CCR9 mAb and CCL27-Fc chimera protein, respectively. (a) The mean fluorescence intensity (MFI) of the indicated surface markers on PP or $\mathrm{CP}$ IgA ${ }^{+}$cells is shown. Each symbol represents an individual mouse, and horizontal bars indicate the mean.

(b) Histograms gated on IgA ${ }^{+}$B220 ${ }^{+}$cells from PP or CP. Solid line: CCR9 expression or CCL27 binding, grey histogram: human IgG Fc or isotype control. $(\mathbf{c}, \mathbf{d})$ Induction of CCR9 and CCR10 on IgA ${ }^{+}$cells by GALT-DCs. CD11c ${ }^{+}$cells were isolated from PP and CP of mice injected with B16 melanoma cells secreting Flt3L. Splenic naive B cells were cultured in the presence of antibody to IgM alone or with CP-derived DCs (CP-DC) or PP-derived DCs (PP-DC). After 4 days, B cells were analysed for CCR9 expression and CCL27 binding. (c) Each symbol represents an individual mouse, and horizontal bars indicate the mean. (d) Representative dot blots gated on B220 ${ }^{+}$cells are shown. Statistical analyses were performed with the Student's $t$-test.

${ }^{\star} P<0.05$. ${ }^{\star} P<0.005$, NS, not significant.

healthy state. In contrast, surgical operation of the appendix in germ-free mice did not cause inflammation because of an absence of microbiota, and the sutured wounds were almost completely closed within 1 week without any sign of inflammation. In addition, resection of the appendix did not cause dramatic reduction of the luminal space of the caecum as shown in Supplementary Fig. 2. This enabled us to investigate the development of mucosal immunity in appendectomized mice after conventionalization.

In accordance with the decreased number of IgA-secreting cells in the large intestine, the composition of faecal microbiota altered in appendectomized mice at 4 weeks after conventionalization. Therefore, as has been reported in the small intestine ${ }^{7,8,12}$, generation of IgA-secreting cells appears responsible for the maintenance of microbial homeostasis in the large intestine. Intriguingly, appendectomized mice at the early time point after conventionalization showed diverse patterns of microbial communities between individuals, whereas sham-operated mice contained microbiota that were highly homogeneous to each other. Thus, colonic secretory IgA contributes to shaping the microbial patterns characteristic of mice.

IgAs in the small and large intestines have been reported to possess differential repertoires ${ }^{15}$. The differential diversities are thought to occur before plasma cell recruitment to the small and large intestines ${ }^{15}$. However, the events that govern the generation of distinct specificities of IgA remain unknown. The present study provides evidence that the caecal patch is the major site for the generation of plasmablasts migrating to both the small and large intestines, whereas Peyer's patches are areas that generate plasmablasts that show preferential migration to the small intestine. Secretory IgA, which has differential diversities between the small and large intestines, has been shown to control gut microbiota ${ }^{5,7-9,12}$. As has been reported in the human intestine $\mathrm{s}^{33}$, the caecum showed a similar pattern of bacterial 
a
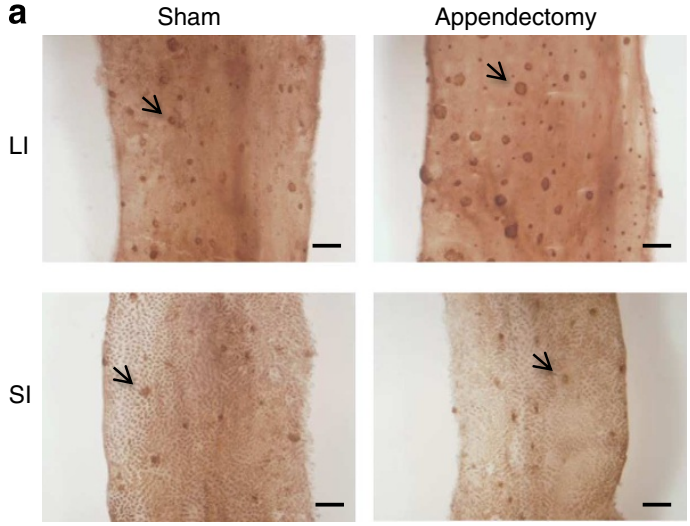

b

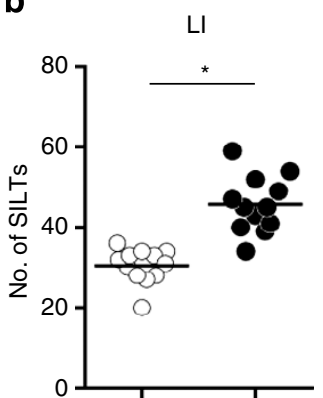

O Sham - Appendectomy
Figure 7 | Increased numbers of isolated lymphoid clusters in the colon of appendectomized mice. (a) SILTs were visualized based on $\mathrm{B} 22 \mathrm{O}^{+}$ clusters (arrows) of whole-mount staining of intestines. Representative photos are shown. (b) Numbers of SILTs per surface of intestines (in a $25 \mathrm{~mm}$ square) are shown (12 mice analysed). Each symbol represents an individual mouse, and horizontal bars indicate the mean. Original magnification: $\times 7$. Scale bars, $1 \mathrm{~mm}$. SI: small intestine, LI: large intestine. Statistical analyses were performed with the Student's $t$-test. ${ }^{\star} P<0.05$. NS, not significant.

composition to the large intestine. Thus, it is supposed that $\operatorname{IgA}$ generated in the caecal patch, which is exposed to the large intestine-types of microbiota, controls microbiota composition in the large intestine. However, at 8 weeks after conventionalization, microbiota composition was normalized in the large intestine of mice with appendectomy. Therefore, IgA generated in lymphoid tissues other than the caecal patch also contributes to the maintenance of microbiota homeostasis. Indeed, colonic SILTs including ILFs increased in mice with appendectomy.

The chemokine receptors CCR9 and CCR10 have been shown to mediate the migration of IgA-secreting plasmablasts to the intestine. CCR9 is responsible for the homing to the small intestine $^{16}$, whereas CCR10 contributes to the migration to both the small and large intestines ${ }^{17,34,35}$. IgA ${ }^{+}$cells in the caecal patch expressed higher levels of CCR9 and CCR10 than the cells in Peyer's patches. Therefore, the higher expression of CCR10 on IgA-secreting cells generated in the caecal patch might be responsible for the preferential migration to the large intestine compared with cells instructed in Peyer's patches. In accordance with the finding that DCs residing in Peyer's patches induce generation of IgA-secreting cells and expression of CCR9 (ref. 32), DCs residing in the caecal patch induced enhanced levels of CCR10. Thus, IgA-secreting cells generated in the caecal patch might be programmed to migrate to the large intestine with enhanced CCR10 expression. CD11c ${ }^{+}$DCs residing in Peyer's patch and the caecal patch showed differential activity in terms of CCR10 induction on $\operatorname{IgA}{ }^{+}$cells. It would be an interesting future study to analyse the mechanisms of the differential properties of DCs residing in Peyer's patch and the caecal patch.

In contrast to the decreased number of IgA-secreting cells observed in the large intestine of appendectomized mice, the number of $\mathrm{CD}^{+}{ }^{+} \mathrm{T}$ cells producing IFN- $\gamma$, IL-17 or IL-10 in the small and large intestines did not change. In this regard, several unique subsets of intestinal DCs that instruct development of Th1, Th17 or regulatory T cells have been identified ${ }^{36}$. These DCs reside in the lamina propria to sample luminal antigens, and migrate to mesenteric lymph nodes, where they induce effector and regulatory $\mathrm{CD}_{4}{ }^{+} \mathrm{T}$ cells ${ }^{37-39}$. Thus, unlike IgA-secreting cells, development of helper and regulatory $\mathrm{T}$ cells are mediated by DCs that reside in the lamina propria. Therefore, the absence of the caecal patch did not affect T-cell development in the intestine.

ILF has been shown to contribute to T-cell-independent IgA synthesis, the mechanism of which is different from that observed in Peyer's patches ${ }^{26}$. In addition, ILFs have been shown to increase in number in the small and large intestines of mice lacking CCR10, which show normal numbers of IgA-secreting cells in the intestine ${ }^{17}$. Enlarged ILFs are considered to serve to compensate for the defective recruitment of $\mathrm{Ccr} 10^{-/-} \mathrm{IgA}$ secreting cells to the intestine. Similarly to $\mathrm{Cr} 10^{-/-}$mice, the number and size of ILFs in the large intestine increased in appendectomized mice in the current study. However, unlike Ccr $10^{-1-}$ mice, which showed increased and enlarged SILTs in the small intestine, SILTs did not increase in the small intestine of mice with appendectomy after bacterial colonization. In this regard, CCR $10^{+} \mathrm{IgA}^{+}$cells generated in the colonic SILTs might be able to migrate to both the small and large intestine in our study. However, in the absence of CCR10, IgA ${ }^{+}$cells generated in the enlarged colonic SILTs were impaired in the migration to the small intestine and therefore SILTs in the small intestine might be enlarged in $\mathrm{Ccr} 10^{-1-}$ mice.

Collectively, our results demonstrate that a lymphoid organ in the appendix is a major tissue generating $\operatorname{IgA}{ }^{+}$cells migrating to the large intestine. Peyer's patches and the caecal patch have distinct properties in terms of induction of $\operatorname{IgA}^{+}$cells with differential migratory directions. This might correlate with the distinct functions of secretory IgAs in the small and large intestines. The precise characterization of IgA generated in Peyer's patches and the caecal patch will reveal how differential IgA repertoires between the small and large intestines are generated in the future.

\section{Methods}

Mice. C57BL/6J mice and CD45.1 congenic mice of the C57BL/6 background (6-8-week old) were purchased from Japan SLC and Sankyo Laboratories Japan, respectively. ALY/NscJcl-aly (aly/aly) and ICR mice were from CLEA Japan. Kaede-transgenic mice ${ }^{29}$ were kindly provided by Dr Michio Tomura (Kyoto University). These mice were kept under specific-pathogen-free conditions at the Experimental Animal Facility, Graduate School of Medicine, Osaka University. Germ-free (IQI/Jic[Gf] ICR) mice were from CLEA Japan and maintained under germ-free conditions. Tcrb ${ }^{-1-}$ Tcrd ${ }^{-1-}$ (refs 40,41) and Rorc $(g t)^{\text {gfp/gfp }}$ mice ${ }^{42}$ of the C57BL/6 background were from Jackson Laboratory, and maintained at the Experimental Animal Facility, Institute of Medical Science, The University of Tokyo. Both male and female mice were used for the all experiments. All animal experiments were performed in accordance with the guidelines of Osaka University Animal Experiment and the Animal Care and Use Committee, The University of Tokyo.

Antibodies. FITC anti-IgM (1B4B1) and Phycoerythrin (PE) anti-IgA (11-44-2) mAbs were purchased from Southern Biotech. Pacific Blue anti-CD45R/B220 (RA3-6B2), FITC anti-CD45R/B220 (RA3-6B2), unlabelled anti-CD16/32 (2.4G2), biotin anti-IgA (C10-1), FITC anti-IgA (C10-3), APC rat $\operatorname{IgG}_{2 \mathrm{a}}$ isotype, APC antiCD138/Syndecan-1 (281-2) and PE anti-CD11c (HL3) mAbs were from BD Biosciences. PerCP/Cy5.5 anti-CD4 (GK1.5), PE anti-IL-10 (JES5-16E3), Alexa Fluor 647 anti-IL-17A (TC11-18H10.1), FITC anti-IFN- $\gamma$ (XMG1.2), APC/Cy7 anti-CD45R/B220 (RA3-6B2), Pacific Blue anti-CD45.2 (clone 104), Pacific Blue 
anti-CD11b (M1/70), Alexa Fluor 647 anti-mouse CCR9 (CW-1.2) mAbs and Alexa Fluor 647 mouse IgG $\mathrm{I}_{2 \mathrm{a}}$ were from Biolegend. Human CCL27-Fc and controlFc chimera proteins were as described previously ${ }^{34}$. Briefly, 293T cells were transfected with the CCL27-Fc and control-Fc expression vectors using Lipofectamine 2000 (Invitrogen). The culture supernatants containing these chimera proteins were collected and used for the experiments.

Quantitative real-time PCR. Total RNA was extracted with TRIzol reagent (Life Technologies). After treated with RQ1 DNase I (Promega), total RNA was reverse transcribed using M-MLV reverse transcriptase (Promega) and random primers (Toyobo). Complementary DNA was analysed by qPCR using GoTaq qPCR Master Mix (Promega) and an ABI 7300 system (Applied Biosystems). All values were normalized against the amount of glyceraldhyde-3-phosphate dehydrogenase (GAPDH) in each sample. Amplification conditions were: $50^{\circ} \mathrm{C}(2 \mathrm{~min}), 95^{\circ} \mathrm{C}$ $(10 \mathrm{~min})$ and 40 cycles of $95^{\circ} \mathrm{C}(15 \mathrm{~s})$ and $60^{\circ} \mathrm{C}(60 \mathrm{~s})$. The following primer sets were used:Gapdh, $5^{\prime}$-CCTCGTCCCGTAGACAAAATG- $3^{\prime}$ and $5^{\prime}$-TCTCCACTT TGCCACTGCAA- $3^{\prime} ; \operatorname{Tnfs} f 13,5^{\prime}$-AGACATTGTACGAGTCTGGGA- $3^{\prime}$ and $5^{\prime}$-TCCCTTGTCCTTCCCGAGATA- $3^{\prime}$; Tnfsf $13 c 5^{\prime}$-ATAGTGGTGAGGCAAAC AGGC- $3^{\prime}$ and $5^{\prime}$-CGTCCCCAAAGACGTGTACTT- $3^{\prime}$; Aicda, $5^{\prime}$-AACCAGACA ACTTCGGCGCAT- $3^{\prime}$ and $5^{\prime}$-TCATCACGTGTGACATTCCAG- $3^{\prime}$.

Immunohistological staining. Collected tissues were fixed with $4 \%$ paraformaldehyde for $1 \mathrm{~h}$ at $4{ }^{\circ} \mathrm{C}$. After washing, tissues were incubated in a $30 \%$ sucrose solution overnight at $4{ }^{\circ} \mathrm{C}$, and embedded in OCT compound (Sakura Finetech). Frozen sections of lymphoid tissues $(10 \mu \mathrm{m})$ were blocked with PBS containing $0.5 \%$ Triton X-100 (PBS-T) and 3\% bovine serum albumin (BSA), and incubated with APC anti-CD11c $\left(5 \mu \mathrm{g} \mathrm{ml}^{-1}\right)$, FITC anti-CD45R/B220 $\left(5 \mu \mathrm{g} \mathrm{ml}^{-1}\right)$ and biotin anti-CD4 mAbs $\left(5 \mu \mathrm{g} \mathrm{ml}^{-1}\right)$, followed by streptavidin-Alexa Fluor 568 (Life Technologies) $\left(2 \mu \mathrm{g} \mathrm{ml}^{-1}\right)$. Alternatively, frozen sections were incubated with FITC anti-IgA $\left(5 \mu \mathrm{g} \mathrm{ml}^{-1}\right)$.The sections were incubated with DAPI (Vector Laboratories), and analysed using a confocal microscope (FV1000-D; Olympus).

Surgical procedure. In appendectomized groups, germ-free mice underwent incision ( $2 \mathrm{~cm}$ in length) on the abdomen under anaesthesia, and the appendix was gently pulled out, ligated with 5-0 Polydioxanone Suture (Ethicon) at the border between the appendix and caecum, and resected in a vinyl isolator. This procedure ensured complete removal of appendix lymphoid tissues and minimized contamination. The caecal stump was irrigated with PBS and the wound was closed. In sham-operated groups, germ-free mice underwent incision of the abdomen and the wound was closed without further treatment. After surgery, mice were maintained under germ-free condition for 1 week. Mice were then transferred to specificpathogen-free conditions and kept for 2, 4 or 8 weeks (see also Supplementary Figs 2 and $5 \mathrm{a}$ ). The appendectomized mice were kept separately from the shamoperated mice. Each group was housed in one cage.

Isolation of lymphocytes. To prepare lymphocytes from Peyer's patches and caecal patches, tissues were gently squeezed between glass slides, and the cells were passed through $40 \mu \mathrm{m}$ nylon meshes. Intestinal lamina propria lymphocytes were prepared as described previously ${ }^{43}$. Briefly, the small and large intestines were opened, washed to remove faecal content, shaken in HBSS containing $5 \mathrm{mM}$ EDTA for $20 \mathrm{~min}$ at $37^{\circ} \mathrm{C}$ and cut into small pieces, and incubated with RPMI 1640 containing $4 \%$ fetal bovine serum (FBS), $1 \mathrm{mg} \mathrm{ml}^{-1}$ collagenase D (Roche), $0.5 \mathrm{mg} \mathrm{ml}^{-1}$ dispase (Invitrogen) and $40 \mathrm{\mu g} \mathrm{ml}^{-1}$ DNase I (Roche) for $1 \mathrm{~h}$ at $37^{\circ} \mathrm{C}$ in a shaking water bath. The digested tissues were subjected to Percoll densitygradient $(40 \% / 70 \%)$ centrifugation. The lamina propria lymphocytes were collected at the interface of the Percoll gradient.

Intracellular cytokine staining. Intracellular expression of IFN- $\gamma$, IL-17 and IL-10 in $\mathrm{CD} 4^{+} \mathrm{T}$ cells was analysed using a Cytofix/Cytoperm Kit Plus (BD Biosciences) according to the manufacturer's instructions. Briefly, lymphocytes obtained from the intestinal lamina propria were incubated with $50 \mathrm{ng} \mathrm{ml}^{-1}$ of phorbol myristate acetate (Sigma), $5 \mu \mathrm{M}$ of calcium ionophore A23187 (Sigma) and Golgistop at $37^{\circ} \mathrm{C}$ for $4 \mathrm{~h}$. Cells were incubated with PerCP/Cy5.5 anti-CD4 mAb $\left(2 \mu \mathrm{g} \mathrm{ml}{ }^{-1}\right)$. After Fix/Perm treatment for 20 min, intracellular cytokine staining was performed with PE anti-IL-10 $\left(2 \mu \mathrm{g} \mathrm{ml}^{-1}\right)$, FITC anti-IFN- $\gamma\left(5 \mu \mathrm{g} \mathrm{ml}^{-1}\right)$ and Alexa Fluor 647 anti-IL-17A $\left(5 \mu \mathrm{g} \mathrm{ml}^{-1}\right) \mathrm{mAbs}$ for $20 \mathrm{~min}$.

Flow cytometry. Cells were treated with anti-CD16/32 $\mathrm{mAb}\left(10 \mu \mathrm{g} \mathrm{ml}^{-1}\right)$ in PBS containing $2 \%$ FBS to block nonspecific binding, and incubated with the indicated mAbs. Samples were incubated with 7 -amino-actinomycinD $\left(1 \mu \mathrm{g} \mathrm{ml}^{-1}\right)$ to exclude dead cells before analyses. Flow cytometry was performed using a FACSCanto II flow cytometer (BD Biosciences) with FlowJo software (Tree Star). To measure the absolute number of $\mathrm{CD} 4{ }^{+} \mathrm{T}$ cell subsets and surface $\mathrm{IgA}^{+}$cells in the intestine, total number of cells isolated from tissues was counted, and then proportion of each cell population was determined by flow cytometry. The number of $\mathrm{CD}^{+}{ }^{+} \mathrm{T}$ cell subsets and surface IgA ${ }^{+}$cells was calculated as 'total cell number' $\times$ 'percentage in flow cytometry'. For cell isolation, cells were sorted using FACSAria (BD Biosciences).

Measurement of IgA. To prepare faecal samples, faeces were homogenized in PBS (1 $\mathrm{mg}$ faeces in $10 \mathrm{ml} \mathrm{PBS}$ ), and subjected to stepwise centrifugation with increasing force ( $400 \mathrm{~g}$ for $5 \mathrm{~min}, 8,000 \mathrm{~g}$ for $10 \mathrm{~min}$ and $19,000 \mathrm{~g}$ for $10 \mathrm{~min}$ ) to remove debris. To prepare mononuclear cells in tissues, Peyer's patches and the caecal patch were shaken for $20 \mathrm{~min}$ at $37^{\circ} \mathrm{C}$ in HBSS containing $5 \mathrm{mM}$ EDTA to remove epithelial cells. The tissues were digested with $1 \mathrm{mg} \mathrm{ml}^{-1}$ Collagenase $\mathrm{D}$ (Roche Diagnostics) and applied to a discontinuous 40 and $70 \%$ Percoll density gradient (GE Healthcare). The mononuclear cells were then cultured for 3 days and the culture supernatants were collected. IgA levels in the faeces, sera and culture supernatants were determined by a mouse IgA ELISA quantitation kit (Bethyl Laboratories). Optical densities were determined at a wavelength of $450 \mathrm{~nm}$ with a reference wavelength of $570 \mathrm{~nm}$.

Extraction of bacterial DNA from faeces. Faeces were collected in collection tubes containing RNAlater (Ambion). After weighing, RNAlater was added to make a 10-fold diluted faecal homogenate. The homogenate $(200 \mu \mathrm{l})$ was washed twice with $1 \mathrm{ml}$ PBS. Glass beads ( $0.3 \mathrm{~g}$; diameter, $0.1 \mathrm{~mm}$; (BioSpec Products), $300 \mu \mathrm{l}$ Tris-SDS solution and $500 \mu \mathrm{l} \mathrm{TE}$-saturated phenol were added to the suspension, and the mixture was vortexed vigorously for $30 \mathrm{~s}$ using a FastPrep-24 (MP Biomedicals) at 5.0 power level for $30 \mathrm{~s}$. After centrifugation at $20,000 \mathrm{~g}$ for $5 \mathrm{~min}$ at $4^{\circ} \mathrm{C}, 400 \mu \mathrm{l}$ of the supernatant was collected. Subsequently, phenol-chloroform extraction was performed and $250 \mu \mathrm{l}$ of the supernatant was subjected to isopropanol precipitation. Finally, the DNA was suspended in $200 \mu$ of TE buffer and stored at $-20^{\circ} \mathrm{C}$.

Determination of microbiota by $16 \mathrm{~S}$ rRNA pyrosequencing. PCR was per formed using a primer set (784F: $5^{\prime}$-AGGATTAGATACCCTGGTA- $3^{\prime}$ and 1061R $5^{\prime}$-CRRCACGAGCTGACGAC-3') targeting the V5-V6 region of the 16S rRNA genes $^{44}$. To amplify the targeted region, $1 \mu \mathrm{l}$ of extracted DNA served as the template in $50 \mu \mathrm{l}$ reactions using KAPA HiFi HS Ready Mix (KAPA Biosystems). PCR conditions were $95^{\circ} \mathrm{C}$ for $3 \mathrm{~min}, 25$ cycles at $98^{\circ} \mathrm{C}$ for $20 \mathrm{~s}, 60^{\circ} \mathrm{C}$ for $15 \mathrm{~s}$ and $72^{\circ} \mathrm{C}$ for $15 \mathrm{~s}$. Two $100-\mu \mathrm{l}$ three-cycle reconditioning PCR reactions were performed per sample to eliminate heteroduplexes, with $10 \mu \mathrm{l}$ aliquots of the initial PCR product mixture as the template and other PCR conditions unchanged. Products of the two reconditioning PCR reactions per sample were combined and purified using DNA clean and Concentrator-5 (Zymo Research). Amplified PCR products were used as a template for pyrosequencing with the GS Junior platform (Roche). Pyrosequencing was performed by following the manufacturer's instruction using MID tags. Raw sequences were demultiplexed and qualitytrimmed using the QIIME pipeline ${ }^{45}$ with default parameters. The trimmed sequences were denoised using AmpliconNoise version 1.2.7 (ref. 46). USEARCH version 6.0.203 (ref. 47) was employed to remove chimaera sequences using the SILVA 111 database ${ }^{48}$ as a reference. The processed sequences were then clustered into OTU defined at $97 \%$ similarity cutoff using UCLUST version $1.2 .22 q$ (ref. 47). Representative sequences for each OTU were classified taxonomically using RDP Classifier version 2.2 (ref. 49) with the SILVA 111 database. Rarefaction curves and UniFrac (ref. 50) distance matrixes were generated using the QIIME tool. The relative abundance was represented as the ratio of the bacterial group to the whole microbiota.

Photoconversion. Kaede bone marrow chimeric mice were generated by intravenous injection of Kaede-labelled bone marrow cells $\left(2 \times 10^{6}\right)$ into 9.5-Gy-irradiated wild-type C57BL/6 mice. Mice were allowed to reconstitute for at least 6 weeks before experimental procedures. For photoconversion, mice were anaesthetized with isoflurane, and a skin incision was made in the abdominal skin to expose Peyer's patches and caecal patches. The surrounding tissue was covered with aluminium foil to prevent unnecessary exposure, and the tissues were exposed to violet light $\left(200 \mathrm{~mW} \mathrm{~cm}^{-2}\right)$ with a 436 -nm g-line band-pass filter with spot UV curing equipment (SP500; Usio) for $5 \mathrm{~min}$. The abdominal wall was closed by 9-mm Autoclips (Clay Adams).

Adoptive transfer experiments. $\mathrm{B} 220^{+}$cells were positively separated using the MACS separation system (Miltenyi Biotec) from Peyer's patches and caecal patches of CD45.2 mice. Sorted cells $\left(1 \times 10^{6}\right)$ were intravenously injected into C57BL/6 CD45.1 recipients through the retro-orbital plexus. Seven days after injection, the lymphocytes were isolated from the small and large intestinal lamina propria and analysed using a flow cytometer.

B-cell activation and coculture with GALT-DCs. To prepare GALT-DCs, C57BL/ 6 mice were injected s.c. with B16 cells secreting Flt3L as described ${ }^{51}$. After 14 days of the injection, Peyer's patches and caecal patches were isolated and digested with RPMI1640 containing 4\% FBS, $1 \mathrm{mg} \mathrm{ml}^{-1}$ collagenase D (Roche Diagnostics) and $40 \mu \mathrm{g} \mathrm{ml}^{-1}$ DNase I (Roche Diagnostics) for $30 \mathrm{~min}$ at $37^{\circ} \mathrm{C}$. Cells were spun through a $17.5 \%$ Accudenz solution (Accurate Chemical \& Scientific Corporation). 
Obtained cells were incubated with PE anti-CD11c $\left(2 \mu \mathrm{g} \mathrm{ml}^{-1}\right)$ and subjected to cell sorting (FACSAria). CD11c ${ }^{+}$cells with $>95 \%$ purity were used for the experiments. Naive $B$ cells were purified from the spleen by negative selection using anti-CD43 microbeads (Miltenyi Biotec). Purified naive B cells $\left(5 \times 10^{5}\right)$ were cultured in the presence of $10 \mu \mathrm{g} \mathrm{ml}{ }^{-1}$ anti-mouse IgM F(ab') (Jackson $^{\prime}$ ImmunoResearch) alone or with equivalent numbers of Peyer's patch-derived or caecal patch-derived DCs for 4 days $^{32}$.

Whole-mount microscopic analysis. Whole-mount microscopic analysis was performed as described previously ${ }^{52}$. Briefly, the small and large intestines were removed intact, opened along the mesenteric border, flushed with PBS and mounted in $8-\mathrm{cm}$ segments from proximal to distal. Samples were then incubated in Hank's balanced salt solution containing $5 \mathrm{mM}$ EDTA at $37^{\circ} \mathrm{C}$ with shaking for $10 \mathrm{~min}$ to remove epithelial cells, followed by washing with cold PBS. Samples were fixed in $4 \%$ paraformaldehyde for $1 \mathrm{~h}$, washed with PBS-T and incubated with $1 \%$ $\mathrm{H}_{2} \mathrm{O}_{2}$ in methanol to block endogenous peroxidases. Samples were then incubated with PBS-T containing $3 \%$ BSA for 30 min with shaking, and incubated with anti$\mathrm{CD} 45 \mathrm{R} / \mathrm{B} 220 \mathrm{mAb}\left(5 \mu \mathrm{g} \mathrm{ml}^{-1}\right)$ overnight at $4{ }^{\circ} \mathrm{C}$, followed by HRP-conjugated $\mathrm{F}\left(\mathrm{ab}^{\prime}\right)_{2}$ goat anti-rat IgG Ab (Jackson ImmunoResearch) $\left(1 \mu \mathrm{g} \mathrm{ml}^{-1}\right)$ at room temperature for $1 \mathrm{~h}$. Signals were developed with Metal Enhanced DAB substrate (Thermo Scientific). Samples were analysed using an Olympus stereo microscope SZX-12.

Statistical analysis. Differences between control and experimental groups were evaluated using the Student's $t$-test. A $P$ value $<0.05$ was considered statistically significant. Data are presented as mean \pm s.d. Mann-Whitney $U /$ Wilcoxon rank sum tests were conducted to assess significant differences in relative abundance of specific OTU obtained by microbiota analysis. For multivariate analyses of data, principal component analysis was used to visualize data sets by statistical programming language R 2.1.5. Between-class analysis and principal coordinate analysis were calculated using the R package 'ade4'. In the UniFrac analysis, ANOSIM was calculated using R package 'vegan'.

\section{References}

1. Cerutti, A. \& Rescigno, M. The biology of intestinal immunoglobulin A responses. Immunity 28, 740-750 (2008).

2. Pabst, O. New concepts in the generation and functions of IgA. Nat. Rev. Immunol. 12, 821-832 (2012).

3. Macpherson, A. J., Geuking, M. B. \& McCoy, K. D. Homeland security: IgA immunity at the frontiers of the body. Trends Immunol. 33, 160-167 (2012).

4. Macpherson, A. J., Geuking, M. B., Slack, E., Hapfelmeier, S. \& McCoy, K. D. The habitat, double life, citizenship, and forgetfulness of IgA. Immunol. Rev. 245, 132-146 (2012).

5. Strugnell, R. A. \& Wijburg, O. L. The role of secretory antibodies in infection immunity. Nat. Rev. Microbiol. 8, 656-667 (2010).

6. Latiff, A. H. \& Kerr, M. A. The clinical significance of immunoglobulin A deficiency. Ann. Clin. Biochem. 44, 131-139 (2007).

7. Fagarasan, S. et al. Critical roles of activation-induced cytidine deaminase in the homeostasis of gut flora. Science 298, 1424-1427 (2002).

8. Suzuki, K. et al. Aberrant expansion of segmented filamentous bacteria in IgA-deficient gut. Proc. Natl Acad. Sci. USA 101, 1981-1986 (2004).

9. Peterson, D. A., McNulty, N. P., Guruge, J. L. \& Gordon, J. I. IgA response to symbiotic bacteria as a mediator of gut homeostasis. Cell Host Microbe 2, 328-339 (2007).

10. Maruya, M., Kawamoto, S., Kato, L. M. \& Fagarasan, S. Impaired selection of IgA and intestinal dysbiosis associated with PD-1-deficiency. Gut Microbe 4, 165-171 (2013).

11. Kawamoto, S. et al. The inhibitory receptor PD-1 regulates IgA selection and bacterial composition in the gut. Science 336, 485-489 (2012).

12. Fritz, J. H. et al. Acquisition of a multifunctional IgA + plasma cell phenotype in the gut. Nature 481, 199-203 (2012).

13. Sutherland, D. B. \& Fagarasan, S. IgA synthesis: a form of functional immune adaptation extending beyond gut. Curr. Opin. Immunol. 24, 261-268 (2012).

14. Suzuki, K., Kawamoto, S., Maruya, M. \& Fagarasan, S. GALT: organization and dynamics leading to IgA synthesis. Adv. Immunol. 107, 153-185 (2010).

15. Lindner, C. et al. Age, microbiota, and T cells shape diverse individual IgA repertoires in the intestine. J. Exp. Med. 209, 365-377 (2012).

16. Pabst, O. et al. Chemokine receptor CCR9 contributes to the localization of plasma cells to the small intestine. J. Exp. Med. 199, 411-416 (2004).

17. Hu, S., Yang, K., Yang, J., Li, M. \& Xiong, N. Critical roles of chemokine receptor CCR10 in regulating memory IgA responses in intestines. Proc. Natl Acad. Sci. USA 108, E1035-E1044 (2011).

18. Mizoguchi, A., Mizoguchi, E., Chiba, C. \& Bhan, A. K. Role of appendix in the development of inflammatory bowel disease in TCR-alpha mutant mice. J. Exp. Med. 184, 707-715 (1996).

19. Weinstein, P. D., Anderson, A. O. \& Mage, R. G. Rabbit IgH sequences in appendix germinal centers: $\mathrm{VH}$ diversification by gene conversion-like and hypermutation mechanisms. Immunity 1, 647-659 (1994).
20. Dasso, J. F. \& Howell, M. D. Neonatal appendectomy impairs mucosal immunity in rabbits. Cell Immunol. 182, 29-37 (1997).

21. Clark, M. A., Jepson, M. A., Simmons, N. L. \& Hirst, B. H. Differential surface characteristics of $\mathrm{M}$ cells from mouse intestinal Peyer's and caecal patches. Histochem. J. 26, 271-280 (1994).

22. Krieglstein, C. F. et al. Role of appendix and spleen in experimental colitis. J. Surg. Res. 101, 166-175 (2001).

23. Pollard, M. \& Sharon, N. Responses of the Peyer's Patches in germ-free mice to antigenic stimulation. Infect. Immun. 2, 96-100 (1970).

24. Sun, Z. et al. Requirement for RORgamma in thymocyte survival and lymphoid organ development. Science 288, 2369-2373 (2000).

25. Shinkura, R. et al. Alymphoplasia is caused by a point mutation in the mouse gene encoding Nf-kappa b-inducing kinase. Nat. Genet. 22, 74-77 (1999).

26. Tsuji, M. et al. Requirement for lymphoid tissue-inducer cells in isolated follicle formation and $\mathrm{T}$ cell-independent immunoglobulin A generation in the gut. Immunity 29, 261-271 (2008).

27. Tezuka, H. et al. Prominent role for plasmacytoid dendritic cells in mucosal $\mathrm{T}$ cell-independent IgA induction. Immunity 34, 247-257 (2011).

28. Macpherson, A. J. et al. A primitive T cell-independent mechanism of intestinal mucosal IgA responses to commensal bacteria. Science 288, 2222-2226 (2000).

29. Tomura, M. et al. Monitoring cellular movement in vivo with photoconvertible fluorescence protein 'Kaede' transgenic mice. Proc. Natl Acad. Sci. USA 105, 10871-10876 (2008).

30. Mora, J. R. \& von Andrian, U. H. Differentiation and homing of IgA-secreting cells. Mucosal Immunol. 1, 96-109 (2008).

31. Macpherson, A. J. \& Uhr, T. Induction of protective IgA by intestinal dendritic cells carrying commensal bacteria. Science 303, 1662-1665 (2004).

32. Mora, J. R. et al. Generation of gut-homing IgA-secreting B cells by intestinal dendritic cells. Science 314, 1157-1160 (2006).

33. Eckburg, P. B. et al. Diversity of the human intestinal microbial flora. Science 308, 1635-1638 (2005).

34. Hieshima, K. et al. CC chemokine ligands 25 and 28 play essential roles in intestinal extravasation of IgA antibody-secreting cells. J. Immunol. 173, 3668-3675 (2004).

35. Kunkel, E. J. et al. CCR10 expression is a common feature of circulating and mucosal epithelial tissue IgA Ab-secreting cells. J. Clin. Invest. 111, 1001-1010 (2003).

36. Rescigno, M. Intestinal dendritic cells. Adv. Immunol. 107, 109-138 (2010).

37. Niess, J. H. et al. CX3CR1-mediated dendritic cell access to the intestinal lumen and bacterial clearance. Science 307, 254-258 (2005).

38. Farache, J. et al. Luminal bacteria recruit $\mathrm{CD} 103+$ dendritic cells into the intestinal epithelium to sample bacterial antigens for presentation. Immunity 38, 581-595 (2013).

39. McDole, J. R. et al. Goblet cells deliver luminal antigen to $\mathrm{CD} 103+$ dendritic cells in the small intestine. Nature 483, 345-349 (2012).

40. Itohara, S. et al. T cell receptor delta gene mutant mice: independent generation of alpha beta $\mathrm{T}$ cells and programmed rearrangements of gamma delta TCR genes. Cell 72, 337-348 (1993).

41. Mombaerts, P. et al. Mutations in T-cell antigen receptor genes alpha and beta block thymocyte development at different stages. Nature 360, 225-231 (1992).

42. Eberl, G. \& Littman, D. R. Thymic origin of intestinal alphabeta T cells revealed by fate mapping of RORgammat + cells. Science 305, 248-251 (2004).

43. Atarashi, K. et al. ATP drives lamina propria $\mathrm{T}(\mathrm{H}) 17$ cell differentiation. Nature 455, 808-812 (2008).

44. Andersson, A. F. et al. Comparative analysis of human gut microbiota by barcoded pyrosequencing. PLoS ONE 3, e2836 (2008).

45. Caporaso, J. G. et al. QIIME allows analysis of high-throughput community sequencing data. Nat. Methods 7, 335-336 (2010).

46. Quince, C., Lanzen, A., Davenport, R. J. \& Turnbaugh, P. J. Removing noise from pyrosequenced amplicons. BMC Bioinformatics 12, 38 (2011).

47. Edgar, R. C. Search and clustering orders of magnitude faster than BLAST. Bioinformatics 26, 2460-2461 (2010).

48. Quast, C. et al. The SILVA ribosomal RNA gene database project: improved data processing and web-based tools. Nucleic Acids Res. 41, D590-D596 (2013).

49. Cole, J. R. et al. The ribosomal database project (RDP-II): introducing myRDP space and quality controlled public data. Nucleic Acids Res. 35, D169-D172 (2007).

50. Lozupone, C. \& Knight, R. UniFrac: a new phylogenetic method for comparing microbial communities. Appl. Environ. Microbiol. 71, 8228-8235 (2005).

51. Mora, J. R. et al. Selective imprinting of gut-homing T cells by Peyer's patch dendritic cells. Nature 424, 88-93 (2003).

52. Lorenz, R. G., Chaplin, D. D., McDonald, K. G., McDonough, J. S. \& Newberry, R. D. Isolated lymphoid follicle formation is inducible and dependent upon lymphotoxin-sufficient B lymphocytes, lymphotoxin beta receptor, and TNF receptor I function. J. Immunol. 170, 5475-5482 (2003). 


\section{Acknowledgements}

We thank M. Tomura for providing us with Kaede-transgenic mice, M. Maruya for the analysis of IgA-secreting cells, T. Kondo and Y. Magota for the maintenance of the germfree mice and C. Hidaka for secretarial assistance. This work was supported by grants from the Ministry of Education, Culture, Sports, Science and Technology, the Japan Science and Technology Agency, and by the Ministry of Health, Labour and Welfare and The Osaka Foundation for Promotion of Clinical Immunology.

\section{Author contributions}

K.M. performed experiments. E.U., H.K., S.S., M.K., T.K., R.O. and A.T. performed animal experiments. Y.S. and M.T. performed experiments using germ-free mice. M.K., J.K., Y.B., T.K. and M.I. performed the migration experiment. S.N., D.M., T.K., K.G. and

T.I. performed the pyrosequencing experiment. T.H. and O.Y. conducted the Fc-chimera protein experiment. M.F., H.K. and S.F. contributed to the experimental design and data analysis. K.T. planed and directed the research and wrote the paper.

\section{Additional information}

Supplementary Information accompanies this paper at http://www.nature.com/ naturecommunications

Competing financial interests: The authors declare no competing financial interests.

Reprints and permission information is available online at http://npg.nature.com/ reprintsandpermissions/

How to cite this article: Masahata, K. et al. Generation of colonic IgA-secreting cells in the caecal patch. Nat. Commun. 5:3704 doi: 10.1038/ncomms4704 (2014). 